Review

\title{
Flexible Medical Devices: Review of Controllable Stiffness Solutions
}

\author{
Loïc Blanc $^{1, *}$, Alain Delchambre ${ }^{2}$ and Pierre Lambert ${ }^{1}$ \\ 1 TIPs Department, CP165/67, Université Libre de Bruxelles, 50 Av. Franklin Roosevelt, \\ 1050 Brussels, Belgium; pierre.lambert@ulb.ac.be \\ 2 BEAMS Department, CP 165/56, Université Libre de Bruxelles, 50 Av. Franklin Roosevelt, \\ 1050 Brussels, Belgium; alain.delchambre@ulb.ac.be \\ * Correspondence: loic.blanc@ulb.ac.be
}

Received: 22 May 2017; Accepted: 30 June 2017; Published: 11 July 2017

\begin{abstract}
In the medical field and in soft robotics, flexible devices are required for safe human interaction, while rigid structures are required to withstand the force application and accuracy in motion. This paper aims at presenting controllable stiffness mechanisms described in the literature for applications with or without shape-locking performances. A classification of the solutions based on their working principle is proposed. The intrinsic properties of these adaptive structures can be modified to change their mechanical characteristics from a geometrical point of view or equivalent elastic properties (with internal mechanisms or with a change in material properties). These solutions are compared quantitatively, based on selected criteria linked to the medical field as the stiffness range, the activation time and the working conditions. Depending on the application and its requirements, the most suitable solution can be selected following the quantitative comparisons. Several applications of these tunable stiffness structures are proposed and illustrated by examples of the literature.
\end{abstract}

Keywords: controllable stiffness; flexural stiffness; shape-locking; flexible medical devices

\section{Introduction}

Soft tools with controllable stiffness performances can have applications in the medical field, as in Minimally-Invasive Surgery (MIS) in which the endoscopic tools are mainly used [1]. On the one hand, the flexibility of these medical devices is appreciated as they can follow tortuous paths with little to no interaction force with organs and with low risk of damaging tissues or causing pain to the patient, being therefore a safer mode [2]. On the other hand, rigid tools are required during medical interventions to transmit force during punctures, biopsies or grasping tasks, for supporting other tools and to bring accuracy in positioning [2].

These needs can be illustrated with the problems encountered during colonoscopies when the colonoscope forms loops in the colon [3]. The colonoscopes have to be very flexible, but also able to resist buckling [4]. The stiff shafts help for avoiding the loop formation, but not for traveling through a tortuous path (causing more pain when a loop happens), while the flexible shafts can ease the motion through a tortuous path, but cause more frequent apparition of loops. Several solutions exist as use of an overtube, use of stiffening wires in the biopsy channel or switching to/from a pediatric colonoscope via a guidewire, but these solutions may cause complications or increase the duration of the interventions [5]. A controllable stiffness device could solve these issues.

Such adaptive devices can also solve issues in cardio-vascular medicine. The vascular occlusion (cardiovascular disease) is a reduction of the cross-section of a blood vessel. One of the possible interventions for removing this occlusion consists of positioning a stent. In this case, a guidewire has to pass through the occlusion such that a balloon catheter can deliver the stent at the right location [6]. 
Therefore, the guidewire has to be flexible enough to reach the stenosis, having followed a possible tortuous path through the blood vessels. Once it has reached the stenosis and in order to pass through the occlusion, it requires a rigid support to avoid buckling or deformation due to the force application. During treatment of Chronic Total Occlusions (CTO), 63\% of the procedural failures are due to the inability of the guidewires to cross the occlusion [7]. The use of guidewires with controllable stiffness (a flexible state for navigation and a rigid state for force application) would help these interventions, as currently, the guidewires are selected with respect to their fixed properties [8].

Variable stiffness mechanisms can also be applied to other fields as for instance soft robotics. Variable stiffness solutions can be used in robotics for the development of a foot [9], in adaptive vibration damping [10], in bio-engineering for developing extracellular matrix [11], in architectural structures, in haptic interfaces or in robotics and grippers [12]. The change of stiffness can also be used for universal orthopedic casts, customized seatings and adaptive surfaces for aerodynamism properties [13].

In order to solve this duality on the stiffness requirements, various controllable stiffness mechanisms and adaptive structures have been proposed in the literature. This work proposes a review for controllable stiffness solutions. Section 2 proposes a classification of the solutions based on their working principle. This classification is illustrated with examples from the literature. Section 3 gives the requirements of variable stiffness mechanisms for medical applications, but with a general purpose of quantitatively identifying the solutions. Section 4 gives a quantitative comparison of the solutions developed in the literature and introduced in this work. Finally, Section 5 gives examples of applications of the controllable stiffness solutions.

\section{Basic Principles and State of the Art}

The various controllable stiffness solutions can be classified following several criteria such as: stiffness ratio, stiffness range, ultimate or yield stress, activation stimulus, working principle [3] or actuation technology and energy [14,15]. In this review, a first classification based on the working principles influencing the flexural stiffness is introduced and summarized in Table 1. Only the reversible solutions have been selected: it is possible to switch from a flexible state to a rigid one, and inversely, several times. Some solutions are binary (having only two states), while others demonstrate multiple possible stiffness values or even a continuous change in stiffness. Some solutions can be deformed in the flexible state and locked in this configuration by switching to the stiff state (shape-locking), while others are limited to a given shape.

This classification is based on the intrinsic properties of the solutions. The flexural stiffness $\left(E_{b} I\right)$ of a mechanical structure is the ability of a structure to resist bending [16]. It is defined as the product of the elastic modulus in bending $\left(E_{b}\right)$ and the second moment of area $(I)$. It takes therefore into account the intrinsic properties of the material and the geometry of the structure. The first class of solutions is based on these intrinsic properties. Two main families of controllable stiffness solutions based on intrinsic properties of the structure can be defined: the first is based on the change of the second moment of the area of the structure, and the second is based on the change of elastic properties of the structure. Another class represents the active solutions acting like actuators resisting the bending force applied on the structure. 
Table 1. Classification of controllable stiffness mechanisms and solutions. The first two families are based on intrinsic properties change (geometrical and elastic properties). The third family counts the active solutions operating as actuators.

\begin{tabular}{|c|c|c|c|c|c|}
\hline \multicolumn{4}{|l|}{ Classification } & Acronyms & References \\
\hline \multirow{3}{*}{$\begin{array}{l}\text { Geometrical } \\
\text { Properties }\end{array}$} & \multicolumn{3}{|c|}{ Cross-Section Shaping } & CS & [17-19] \\
\hline & \multirow{2}{*}{$\begin{array}{l}\text { Structural } \\
\text { Interactions }\end{array}$} & \multirow{2}{*}{$\begin{array}{l}\text { Multi-Layer } \\
\text { Beam }\end{array}$} & Single material & MLB-S & {$[20-25]$} \\
\hline & & & Multiple materials & MLB-M & {$[26-31]$} \\
\hline \multirow{19}{*}{$\begin{array}{l}\text { Elastic } \\
\text { Properties }\end{array}$} & \multirow{11}{*}{ Material } & \multirow{4}{*}{$\begin{array}{l}\text { Phase } \\
\text { Transition }\end{array}$} & $\begin{array}{l}\text { Low Melting Point } \\
\text { Alloy }\end{array}$ & LMPA & [32-37] \\
\hline & & & $\begin{array}{l}\text { Low Melting Point } \\
\text { Polymer }\end{array}$ & LMPP & {$[13,38-41]$} \\
\hline & & & Wax & & {$[42,43]$} \\
\hline & & & Solder & & {$[44,45]$} \\
\hline & & \multirow{4}{*}{$\begin{array}{l}\text { Glass } \\
\text { Transition }\end{array}$} & Shape Memory Alloy & SMA & {$[46-53]$} \\
\hline & & & $\begin{array}{l}\text { Shape Memory } \\
\text { Polymer }\end{array}$ & SMP & {$[38,47,54-56]$} \\
\hline & & & $\begin{array}{l}\text { Shape Memory } \\
\text { Composite }\end{array}$ & SMC & [57-60] \\
\hline & & & Shape Memory Gel & SMG & [61-64] \\
\hline & & \multirow{2}{*}{$\begin{array}{l}\text { Rheological } \\
\text { Fluids }\end{array}$} & Magnetorheological & MRF & {$[14,65-80]$} \\
\hline & & & Electrorheological & ERF & {$[14,65-68]$} \\
\hline & & \multicolumn{2}{|l|}{ Biomaterials } & $\mathrm{BM}$ & {$[39,81-84]$} \\
\hline & \multirow{8}{*}{$\begin{array}{l}\text { Structural } \\
\text { Interactions }\end{array}$} & \multirow{2}{*}{ Bulk Locking } & Granular Jamming & GJ & {$[12,85-112]$} \\
\hline & & & Turgor Pressure & $\mathrm{TP}$ & [113-121] \\
\hline & & \multirow{4}{*}{$\begin{array}{l}\text { Segments } \\
\text { Locking }\end{array}$} & Central Wire & $\mathrm{CW}$ & [122-124] \\
\hline & & & Multiple Wires & MW & {$[1,2,123,125-129]$} \\
\hline & & & Bellows Connections & $\mathrm{BC}$ & {$[66]$} \\
\hline & & & Soft Layer & SL & {$[130,131]$} \\
\hline & & \multirow{2}{*}{$\begin{array}{l}\text { Longitudinal } \\
\text { Locking }\end{array}$} & Layer Jamming & LJ & {$[111,132-136]$} \\
\hline & & & Wire Jamming & WJ & {$[137,138]$} \\
\hline \multirow{4}{*}{$\begin{array}{l}\text { Actuator-Like } \\
\text { Solution }\end{array}$} & \multirow{2}{*}{ Fluid-based } & \multicolumn{2}{|c|}{ Pneumatic Solution } & PS & {$[19,139-142]$} \\
\hline & & \multicolumn{2}{|c|}{ Fluidic Flexible Matrix Composite } & FFMC & [143-145] \\
\hline & \multicolumn{3}{|c|}{ Mechanical Solution } & MS & [146-150] \\
\hline & \multicolumn{3}{|l|}{ Muscles } & M & [151-153] \\
\hline
\end{tabular}




\subsection{Geometrical Properties}

The stiffness change can be obtained by changing the geometrical properties of the cross-section of the structure, either by modifying the cross-section or by changing the structural interactions of the elements forming the structure.

\subsubsection{Cross-Section Shaping}

The change in cross-section (shape and/or dimensions) leads to a direct change of second moment of area $(I)$ of the structure. This modification can lead to an increase or a decrease of flexural stiffness $\left(E_{b} I\right)$ while keeping the same material properties. Increasing or displacing the amount of material further away from the central axis as illustrated in Figure 1a and expressed by Equation (1) leads to an increase in flexural stiffness $\left(E_{b} I\right)$. In this family, the external dimensions of the structure may be modified. Solutions based on folding mechanisms (e.g., origami [17]), shape memory effect (e.g., polymers [18]), pneumatic expansion (e.g., some fluidic actuators [19]) and other mechanisms can modify their cross-section easily in response to a stimulus. In these cases, no shape-locking is possible, and the initial configuration is the only stable one.

$$
I_{x}=\iint y^{2} \mathrm{~d} A, \quad I_{y}=\iint x^{2} \mathrm{~d} A
$$

with the cross-section plane defined by the $x$ and $y$ axes and $x$ and $y$ are the coordinates of the area element $\mathrm{d} A$ [16].

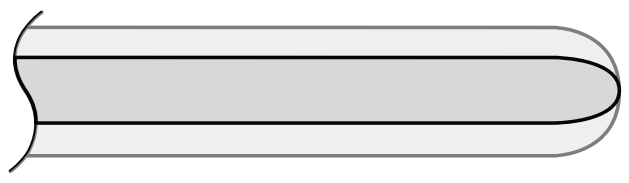

(a)

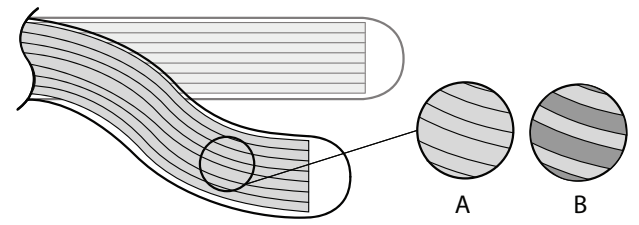

(b)

Figure 1. (a) Cross-section shaping: the cross-section is modified, which causes a change in the second moment of area $I$; (b) structural interactions change: the layers composing the beam may be disconnected or locked with each other, modifying the second moment of area $I$; (A) multi-layer beam made of a single material; (B) multi-layer beam made of multiple materials.

\subsubsection{Structural Interactions}

Another class of solutions can modify their geometrical properties (second moment of area $I$ ) with no change of external dimensions as seen in Figure 1b. The basic principle relies on the interactions between structural elements composing the structure. The structures correspond to multi-layer beams made of a single or multiple materials. The flexural stiffness of multi-layer beams depends on the geometry and the interactions of the layers composing the beam [31]. In the flexible state, the layers are decoupled, and the global second moment of area $(I)$ corresponds to the sum of the one of each layer. In the rigid state, the layers are coupled, and the beam behaves as a single larger beam with a strongly larger second moment of area (I). The locking of the structural elements can be obtained by applying a force (from a pressure difference, the tension of a wire, electrostatics) or by modifying the inter-layers shear properties (by heating, applying an electrical field, etc.).

In the case of solutions based on a "multi-layer beam made of a single material", the change in second moment of area, while keeping the same material properties, leads to a change of stiffness. The second moment of area is modified by adapting the interactions between the layers surfaces during the stiffening process. The beams can be made of thin sheets (bending in one direction) or made of wires with square sections (bending in two directions), placed in a membrane. Decreasing the internal pressure of the membrane locks the linear elements due to the atmospheric pressure in the 
surrounding environment. Micro-machining the surface of the sheets helps change significantly the friction between the sheets and therefore the locking of the elements [20].

Jamming the layers of the beams is performed by electrostatic or pneumatic forces using passive elements in [21]. In the electrostatic application, the polyimide films generate friction on each other due to electrostatic force, and the bending stiffness increases with the voltage. In the pneumatic version, a phase transformation via a micro-heater induces a pressure change in a silicone balloon. In [22], the locking force is induced by Shape Memory Alloy (SMA) wires heated above their transition temperature, while in [23], the buckling of springs are used to lock the layers together.

The "jamSheets" interface is developed for tunable-stiffness display of multimedia content, shape-changing furniture and innovative shoes [24]. This interface is based on multiple thin layers enclosed in a membrane and actuated by a pressure difference. The performances depend on the resistance of the materials composing the sheets to tensile and compressive bending forces. The device becomes more rigid if the vacuum and/or the number of layers is increased [25].

In the case of solutions involving "multi-layer beams made of multiple materials", the mechanical properties of some layers are modified, causing a change in inter-layer interactions and therefore in stiffness. In these solutions, several layers with different materials are used. Rigid materials (typically metallic) are connected via softer intermediate layers (typically polymeric). When the shear modulus of the intermediate layers is high enough, the layers are coupled, and the structure has a large second moment of area $(I)$. When the shear modulus decreases (for example, by heating the polymers), the stiff layers are decoupled leading to a decrease in the second moment of area $(I)$. The bending elastic modulus $\left(E_{b}\right)$ of the intermediate layers is also modified, participating in the change in global stiffness. A multi-layer beam made of two stiff layers separated by a polymeric layer is described in [26]. A flexible heater is used to modify the temperature of the polymer and change its shear behavior in order to couple or decouple the stiff layers. In [27], a Shape Memory Polymer (SMP) demonstrates a variable stiffness element in a sandwich configuration with rigid elements.

\subsection{Elastic Properties}

The structure can be compared to an equivalent homogeneous material with the same dimensions. The change of equivalent elastic properties can be obtained by directly changing elastic properties of the materials composing the solution or by modifying the interactions of its structural elements. It is possible to induce a prestress acting against the external forces by locking multiple elements. Preventing the deformation of the structure can be obtained by locking longitudinal elements as their lengths are fixed, and they cannot slide with respect to each other. It is possible to combine all of these principles to obtain hybrid solutions.

\subsubsection{Material}

In the change of stiffness due to intrinsic material properties, the solutions can be grouped in several categories: phase transition (low melting point materials as wax, alloys or polymers), glass transition (shape memory materials, biological materials) and rheological fluids (electro- and magneto-rheological fluids). The intrinsic properties of a material can be modified by heat, chemical reaction or electro-magnetic field. A review of several thermal-based variable stiffness solutions is proposed in [41,42]. These solutions are based on the use of a matrix (foam, lattice) filled with thermally-reactive fluids (Magnetorheological (MR) fluids, solder, hot glue, wax) or on thermo-responsive materials. In the flexible state (with no field for rheological fluids and above the characteristic temperatures for the phase and glass transition temperature), the structure can be distorted for a lower range of forces. In the rigid state (with field for rheological fluids and below the characteristic temperatures for the phase and glass transition temperature), the structure is locked in the configuration and can resist higher forces than in the previous state. 
The group of materials used in the phase transition-based solutions counts, for instance wax, solder and low melting point material (alloy, polymer).

- Wax: Foam-like structures covered with wax are rigid at ambient temperature and flexible at higher temperature [43]. When these structures are heated up, the wax changes phase, and the structure has the flexibility of the inner structure (e.g., foam). The advantages of this solution are the availability, the low cost and the ease of manufacturing of the elements while performing well.

- Solder: A worm-like robot demonstrates the use of polymeric elements connected by solder-joints for controllable stiffness performances [44]. A crawling robot with "solder-activated joints" uses joints with the phase-change as the locking mechanism [45]. The first phase-change joints (made with hot glue sticks) have been studied by Boston Dynamics. The global stiffness of the device can be adjusted by controlling the temperature of each element and joint. The elements contain thermorheological fluids, while the joints are made of solder-alloy mixture $(60 \mathrm{Sn}-40 \mathrm{~Pb}$ and Chip Quik) to lock or unlock the structure [44].

- Low melting point material: A solution based on Low Melting Point Alloy (LMPA) is presented in [32]. Joule losses are used in a circuit made of Galinstan in the liquid phase at ambient temperature (being therefore a soft heater). A thin layer of Field's metal is heated by the latter circuit to change its phase and therefore its mechanical properties. A solution based on Cerrolow 117, an LMPA, integrated in a PDMS shell uses Joule heating by voltage difference applied on the LMPA for phase transition and stiffness change [34]. Joule heating of Cerrolow 117 embedded in dielectric elastomer is also used for a variable stiffness gripper [35]. An overtube for endoscopic applications based on LMPA is described in [36], using hot water to activate the change in stiffness. Numerous low melting point polymers are available with various transition temperatures $[13,38]$. The performances of such solutions will depend on the design, which could be optimized for obtaining very high performances [39].

Some solutions are based on the glass transition of the materials. The heat transmission can be performed by using a water flow [38,39], air [61], Joule losses [13,62] or magnetic induction [57]. Conducting polymers actuated with low voltages $(<1 \mathrm{~V})$ are used to develop a new catheter in [154]. The latter solution is proposed for actuated catheters with controllable tip orientation.

Smart materials are stimuli-responsive materials. They interact with the environment for example through acoustic, electromagnetic, optical, chemical, thermal or mechanical stimulation [155]. Some smart devices, based on smart materials, can adjust their stiffness. Shape memory materials are materials (alloys, polymers, gels or composites) that can be programmed to change their shape or properties for a given stimulus. Shape memory materials can be used for their shape memory performances (e.g., for actuation) or for their stiffness change ability.

The Shape Memory Alloys (SMA) are metals that can stay in a defined shape and go back to another shape via a heat stimulus. The nickel-titanium (NiTi) alloy is frequently used. For the latter, the elastic modulus (slope of the linear initial elastic region of the stress-strain curve) and the yield stress increase with the temperature [46].

A review of Shape Memory Polymers (SMP) [47] gives a comparison between SMP and SMA. The SMP can present a larger deformation, a larger range of elastic modulus around the transition temperature and a lower cost than the SMA. Electrical elements can be mixed within an SMP to induce Joule losses when a current flows through the SMP, inducing the thermal activation of the polymer. Nanoparticles of iron can allow for magnetic interaction (via magnetic induction and iron losses heating) [57].

Shape Memory Gel (SMG) is used in links of a robot, switching between flexible links (hot SMG) and rigid links (cold SMG) [61,62]. The change of stiffness in SMP is obtained around the glass transition temperature $T_{g}$, while it is obtained around the crystallization temperature for SMG. 
The Magnetorheological (MR) and Electrorheological (ER) fluids change their rheological behavior when subjected to, respectively, a magnetic and an electrical field. The yield stress increases with this external field. These fluids are composed of micrometric scale particles [65]. The main disadvantages of the rheological fluids are sealing, homogeneity and environmental issues [14]. These fluids can be used in variable stiffness solutions. For instance, a locking mechanism based on bellows filled with rheological fluid can change the stiffness of the device presented in [66]. In the soft mode, the bellows can be filled by or emptied of the fluid through a valve. Once the fluid is activated, the bellows are locked in a given configuration. Moreover, the multiplication of microchannels filled with MR fluid permits a better effect for lower fields [69].

Some biomaterials can show effective change in stiffness. The echinoderms (for instance, the sea urchins, the sea cucumbers, the starfish, brittle stars and sea lilies) can modify the stiffness of their skin through quick and reversible collagen fiber linking [39]. The interactions of the collagen fibrils can be regulated by their nervous system such that the stress transfer is modified and therefore the stiffness [81].

A nanocomposite polymer inspired by the ability of the skin of sea cucumber to change its stiffness under a given stimulus is reinforced with cellulose fibers [82]. In the natural state, the result is rigid due to the interactions of the nanofiber through hydroxyl groups. Lowering down these interactions by a chemical regulator leads to a decrease in stiffness. In the sea cucumber, the matrix is filled with collagen fibrils that interact via glycoproteins to adapt its stiffness, while in the new model, the matrix made of polymer is filled with cellulose whiskers that interact with hydrogen bonds. A solution based on PVAc (poly(vinyl acetate)) and cotton cellulose whiskers gives similar results in terms of stiffness change due to the temperature change, but decreases the absorption of water [83].

\subsubsection{Structural Interactions}

In the "bulk locking" mechanisms, the solution is composed of several elements in its volume (in the longitudinal and lateral directions). The change of stiffness is obtained by modifying the interactions of all of these elements. The size of the elements compared to the characteristic dimensions of the structure can range from relatively large (discrete deformation and shape-locking) to very small (almost continuous deformation and shape-locking). With this solution, it is possible to deform the structure in the flexible state and to lock it in a given configuration when switching to the rigid state. The change of interactions can be obtained by electro-magnetic field, pressure difference, force application or chemical reaction.

One of the known applications of bulk locking is called "granular jamming", as illustrated in Figure 2A. The granular jamming solution is based on a granular material embedded in a membrane. The stiffness of the sample can be modified by the pressure difference across the membrane. When the pressure difference is low (the pressure in the sample is close to the pressure of the surrounding environment), the grains are free to move with respect to each other, and the system is flexible [85]. When the pressure difference is increased, the system is more rigid as the grains start to lock with each other. The volume change can be very small to switch from a flexible state to a more rigid state [88]. Various parameters influence the performances of this solution, as the shape, size and material of the particles [12,91,92,96,101,102], the membrane [94] and the configuration of the structure [99]. 


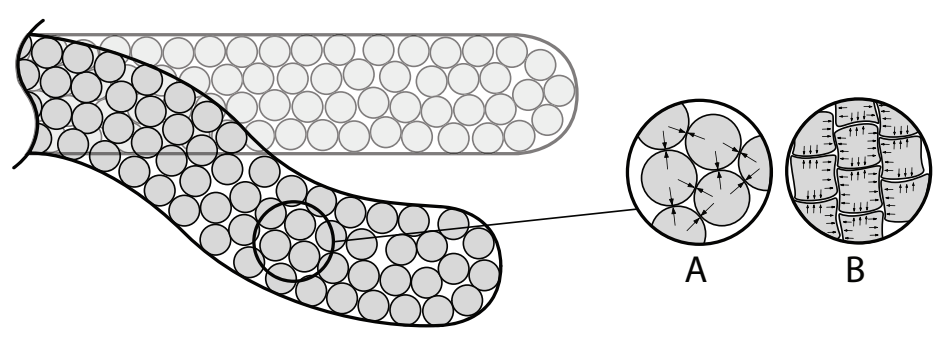

Figure 2. Bulk locking solutions: the arrows represent the interaction forces between the elements. (A) Granular jamming: the grains can be locked with each other due to application of an external force; (B) turgor pressure: inspired by the plant, the elements can be locked with each other due to internal forces influenced by the surrounding environment.

Another solution based on bulk locking is similar to the turgor pressure in plants. The turgor pressure is the pressure exerted by the incompressible fluid filling the cells on their wall [113] as represented in Figure 2B. A model in which the cells are considered as delimited by elastic membranes and filled with water is proposed in $[113,114]$. A model based on foam with closed cells filled with fluid can estimate the value of the elastic modulus as a function of the turgor pressure of carrot tissues [115]. The leaf support depends on the biomechanical characteristics of the petioles [116]. A model to link the bending stiffness and the cell radius is proposed in [116], based on shape transformers and validated by experimental results. The elastic modulus of apple and potato tissues is evaluated in [117], while the hardening of plant food when it is dried is studied in [118]. The bending stiffness of petiole can be evaluated based on the cross-section geometry [119].

In the "segments locking" mechanisms, the structure is divided into several elements over its length. Only one single element lies in the section. The change of stiffness is obtained by modifying the interactions of these segments. The principal stimulus is the tension of longitudinal cables, but other stimuli could also lock the segments as a magnetic field or a difference of pressure.

Several locking principles can be found and are represented in Figure 3. The tension of several wires (A) or a central wire (B) is used to lock the segments and to induce a stiffness change. The segments can be beads [122], cylindrical elements connected by spherical joints $[1,123]$ or rigid cylindrical elements [125]. The change of stiffness comes from the friction between the elements due to the tension in the cables [2]. The tensioning of multiple wires is already used for tip control of medical devices [156] or snake-like robots [2].

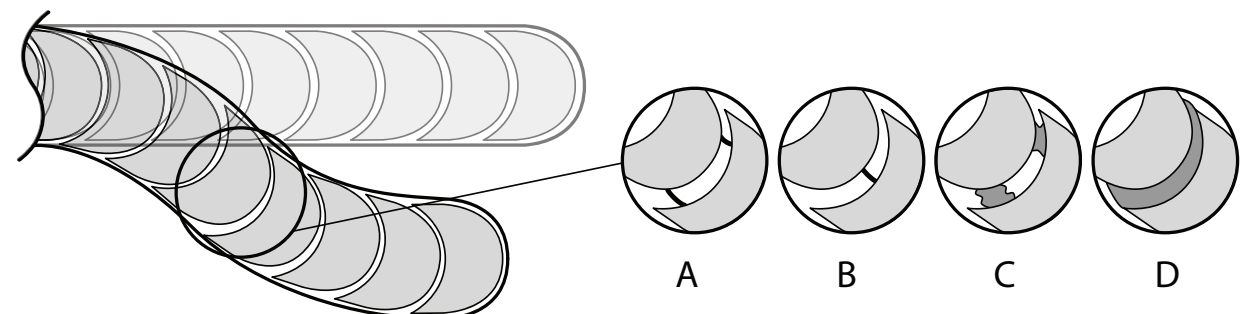

Figure 3. Segments locking solutions: the segments composing the structure can be locked by several inter-segment elements as: (A) multiple tensioning wires; (B) a central tensioning wire; (C) bellows-like connections; (D) soft material layers.

The use of bellows-like segment connectors (C) allows for locking the segment with a defined angle. The use of an inter-segment made of soft material (D) can lead to a locking of the segments over the whole section. The stiffness of a multilayer structure (a rubber layer between two rigid plates) can be modified by its compression [130]. A solution based on an endoskeleton-like structure is proposed in [131]. The endoskeleton-like structure is made of soft and rigid segments. A cable is tensioned, 
which compresses the soft joints, increasing the lateral stiffness of the structure (as the compression of the soft joint decreases the effect of the moment on the bending of the structure).

The size of the segments induces a discrete or almost continuous deformation, depending on the size of the segments. With this solution, it is also possible to deform the structure in the flexible state and to lock it in a given configuration when switching to the rigid state.

In the "longitudinal elements locking" mechanisms, the solution is divided into several elements over its section. The change of stiffness is obtained by modifying the interactions of these elements. These interactions are longitudinal with respect to the structure. The stimuli can be a pressure difference, force application or the phase change of specific materials. The lateral size of the segments induces a discrete or almost continuous deformation. With this solution, it is also possible to deform the structure in the flexible state and to lock it in a given configuration when switching to the rigid state.

The longitudinal elements can be thin plates ("layer jamming") or wires ("wire jamming") as seen in Figure 4. The stiffness increase is due to low or no relative displacement between the longitudinal elements via a locking mechanism. This locking may be induced by friction (a) of flat laminates $[111,132,133]$ or by shape conformity (b) (with texturized surfaces as the "dragon skin" [134] or specific geometries [135] that lock with each other when the elements are mechanically coupled).

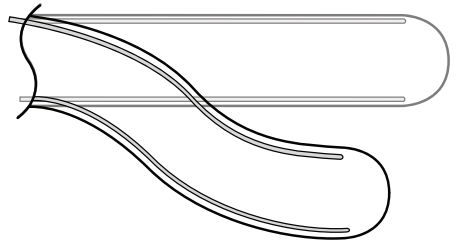

a)

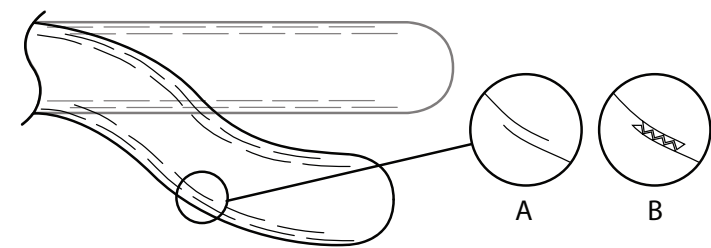

b)

Figure 4. (a) Wire jamming solution: the wire can be free to move giving a flexible state, but once they are locked by an external force, as their length are fixed, the shape is locked and the stiffness is increased; (b) layer jamming solution: the layers are segmented over the length of the solution and can slide over each other in the flexible state, while the rigid state locked them by: (A) friction over flat plates; (B) shape conformity.

A device inspired by the eukaryotic flagellum is proposed for controlling the tip position and orientation and for controlling the global stiffness of a hollow tube [137]. Interlocking fibers are placed in a circular configuration. The sliding of the fibers can be prevented by vacuum, rheological fluids, phase transition material or SMA-clamping. The FORGUIDE mechanism is based on the locking of wires by overpressure [138]. The prototype is made of an external axially-rigid coil, an internal balloon filled with water (that can be pressurized) and wires between the coil and the balloon. These wires can slide in the flexible state to allow for bending and are locked when overpressure is applied in the water.

\subsubsection{Hybrid}

A combination of the previous solutions leads to hybrid solutions. It is possible to change the material properties between some rigid links to ensure a controllable stiffness device [44]. The locking of structural elements can be obtained with rheological fluids or phase transition materials [137].

\subsection{Actuator-Like Solutions}

\subsubsection{Fluid-Based Solutions}

A controllable stiffness solution for robot joints based on air-pressurized chambers is proposed in [139]. A chamber is made of silicone with a braided reinforcement to avoid expansion due to pressurization as schematically represented in Figure 5A. The design of this joint is such that its 
default state is flexible and therefore safe. A module in the STIFF-FLOP (STIFFness controllable Flexible and Learnable manipulator for surgical OPerations) project is tested with several stiffening solutions such as granular jamming, cable-tensioning and air pressurization [140]. The results of the tests showed that the granular jamming gives the stiffest solution while the change of stiffness is larger for the cable-driven solution. Pressurizing the chambers leads to a decrease of stiffness. Another pressurized air-based solution for the STIFF-FLOP project is presented in [141].

The Fluidic Flexible Matrix Composite (FFMC) is another solution based on a fluid (e.g., oil or water [143]) that can achieve variable stiffness. The fluidic channels are embedded in a matrix as schematically represented in Figure 5B. The soft state is obtained when the fluid can flow through the opening of the channels. The stiff state is obtained by closing the entry valve due to the bulk modulus of the pressurized fluid [144]. The blocked state can resist large forces with low pressure in the fluidic network [145].

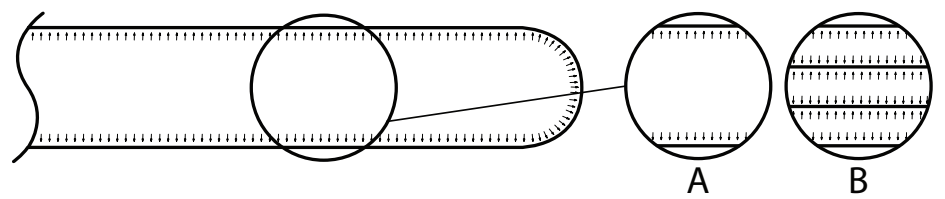

Figure 5. Pressure-based structure: (A) pneumatic structure made of a single chamber; (B) flexible fluidic matrix composite made of several chambers in contact with each other. The arrows represent the pressure acting in the structural elements.

\subsubsection{Mechanical Solutions}

The variation of a lever arm with a spring can lead to the modification of the effective stiffness observed at the end of the arm [146,147]. Several solutions can be adapted by varying the pivot point, the force application and the spring position along the arm. This solution is used in rotation for joints in robotic applications. A variable impedance control allows for having a variable virtual output impedance, as illustrated by the Variable Impedance Differential Actuator (VIDA) in robotics [148]. Electrostatic brakes are used for locking the joints of a robotic hand in a given configuration [149], creating a shape-locking effect and an increase of stiffness through the locking of the joints.

\subsubsection{Muscles}

The change of stiffness is one of the most important characteristics of muscles. Hunter and Lafontaine [151] made a comparison between mechanical actuators and real muscles about their performances (stiffness gain and range, efficiency, density, etc.). The stiffness of muscles and fibers are modeled and measured in [152]. A model for striated muscles [153] shows the increase of muscle's stiffness due to its activation.

\section{Flexible Medical Instruments Requirements}

The review of actuated endoscopic devices in [157] introduces specific requirements and characteristics: diameter, length, bending angle, radius of curvature, number of degrees of freedom and torque. The reviews about variable stiffness solutions in $[3,14,15]$ give the following criteria: speeds of flexible-rigid states change (and the influencing parameters), scalability, stiffness in flexible-rigid states (flexural stiffness, force-displacement characteristics, elastic modulus), stiffness variation, stiffening mode (bending, tension/compression, torsion), ability to deform (tortuous path), ease of use, ease of produce, materials and stimulus.

The goal of a controllable stiffness medical device would be to have a rigid state with a flexural stiffness larger than the stiffest device of the same category currently available on the market, while the flexible state would be softer than the softest device. With this target, the medical tool 
with controllable stiffness would have a larger stiffness range than currently available on the market. For example, a variable stiffness endoscope would have a rigid state stiffer than the most rigid endoscope on the market and a soft state more flexible than pediatric endoscopes (Table A1 gives a review of several endoscopes with their stiffness and their characteristics). Currently, many of the endoscopes have a defined rigidity that cannot be changed [3], and the physician selects the most appropriate endoscope, with a suitable stiffness, for the intervention. The flexural stiffness is the principal quantitative parameter evaluating the performances of controllable stiffness solutions. Other requirements for medical devices can take place in the comparison of the several possible solutions for controlling the stiffness. Table 2 summarizes the quantitative requirements applicable to flexible medical instruments.

Table 2. Requirements for a variable stiffness device applied to endoscopic applications. The values are indicative, give mainly an order of magnitude and may depend on specific requirements related to particular interventions.

\begin{tabular}{cccccc}
\hline $\begin{array}{c}\text { Stiffness } \\
\text { (Rigid State) }\end{array}$ & $\begin{array}{c}\text { Stiffness } \\
\text { (Flexible State) }\end{array}$ & $\begin{array}{c}\text { Ultimate } \\
\text { Force }\end{array}$ & Activation Time & $\begin{array}{c}\text { External } \\
\text { Diameter }\end{array}$ & $\begin{array}{c}\text { Device } \\
\text { Temperature }\end{array}$ \\
\hline$\geq 330 \mathrm{~N} \mathrm{~cm}^{2}$ & $\leq 165 \mathrm{~N} \mathrm{~cm}^{2}$ & $\geq 16 \mathrm{~N}$ & \multirow{2}{*}{ as small as possible } & $\leq 15 \mathrm{~mm}$ & $\leq 41{ }^{\circ} \mathrm{C}$ \\
\cline { 6 - 7 } & {$[158]$} & {$[159]$} & & {$[160]$} & {$[161]$} \\
\hline
\end{tabular}

The ultimate force or stress is also important. It determines when failure may occur. The ultimate force that the structure can resist should be lower than normal forces encountered during medical interventions. These forces influence the design of the medical devices. The forces encountered in normal Natural Orifice Transluminal Endoscopic Surgery (NOTES) procedures ranges between $0.9 \mathrm{~N}$ and 3.3 N [104]. A value of $2.5 \mathrm{~N}$ is needed for insertion of a needle and other classical soft tissue surgery [133,162]. It is recommended in [159] that a NOTES device should be able to work with forces of $16 \mathrm{~N}$.

The speed with which stiffness changes is an important parameter. The fastest solutions are the most attractive [104]. An increase in the duration of a medical intervention represents an increase in cost and risk for the patient.

The scalability of the solution is required for small-sized applications. In Minimally-Invasive Surgery (MIS), the smallest size of tools is required to decrease the inconvenience of the patients. Scaling down solutions may limit their functions and therefore their possibilities. A review of endoscopic tools showed that the outer diameter of commercial endoscopes depends on the type of endoscope (gastroscopes, colonoscopes, duodenoscopes, etc.) [160]. The colonoscopes have diameters up to $15 \mathrm{~mm}$.

The working conditions in which the solution is operating may influence or be influenced by the stimulus causing the stiffness change. For example, if the solution requires being heated, excessive temperatures are not tolerated for medical devices. A maximal surface temperature of $41{ }^{\circ} \mathrm{C}$ is suitable for working in the human body [161]. If a temperature of $48{ }^{\circ} \mathrm{C}$ is applied on the skin, it cannot stay more than $40 \mathrm{~s}$ to avoid skin burning $[58,163]$. The solutions based on pressure differences have also to be limited in their action to be safe for the patient. The use of electrical power should not be too excessive to avoid electrocution.

Biomedical considerations are required for biomedical applications. Use of biocompatible material and biocompatible working conditions is mandatory. Furthermore, disposable devices can have constraints such as production cost and conformity with existing medical devices. Re-usable devices may have less production cost constraints, but cleaning, maintenance and lifetime requirements. Use of toxic materials or, for instance, high fields has to be avoided. An ease of use may be required for a final application in which the physician will have to adopt and use the solution during interventions. 


\section{Specific Characterization}

\subsection{Flexural Stiffness}

The variable stiffness of the solutions can be compared on the range of stiffness that they can reach (from their minimal up to their maximal values) or on the stiffness ratio that can be achieved.

Figure 6 summarizes the comparison of the solutions that have been quantified in the literature and collected in this work. The comparison is based on their stiffness gain defined as:

$$
\eta_{E I}=\frac{E I_{\text {stiff }}}{E I_{\text {flexible }}}
$$

with $E I_{\text {stiff }}$ and $E I_{\text {flexible }}$ the flexural stiffness of the device in rigid and flexible state, respectively. The stiffness change can be very high when specific materials are selected. Solutions based on bulk, segments and longitudinal locking shows limited performances compared to multi-layer beams and material-based solutions.

This stiffness gain $\left(\eta_{E I}\right)$ often depends on the design and dimensions of the structure. For example, when the layers of multi-layer beams are completely locked (the device behaving therefore as a single thick plate), the stiffness gain depends quadratically on the number of layers composing the multi-layer beam [20,22]. As the stiffness change depends on the number of layers, the use of thin and flat layers improves the performances of such solutions [25,164]. The optimal stiffness gain $\eta_{E I}$ of multi-layer beams made of multiple materials is obtained when the stiffness of the coupled beam is high, the intermediate layers of polymer are large and the boundary layers have large stiffness $[29,30]$.

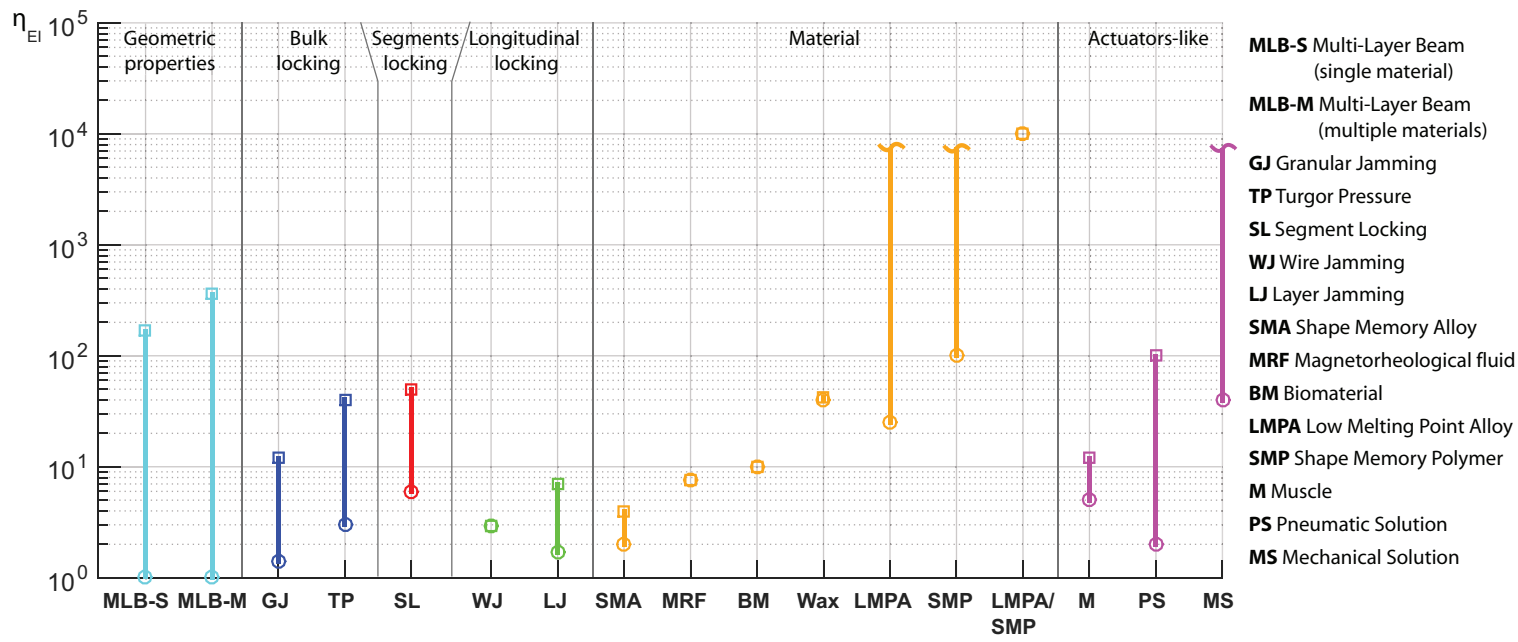

Figure 6. Comparison of the stiffness gain $\eta_{E I}$ for various solutions presented in the literature presented following the classification introduced in this work. Some solutions ("LMPA", "SMP" and "MS") have no upper bound as the literature gives only the lowest stiffness gain they can achieve. The biomaterial value corresponds to the skin of echinoderms.

Currently, most of the endoscopes have a fixed stiffness. An improvement would be to have controllable stiffness endoscopes. In Figure 7, a comparison of endoscopic-like solutions (having a tubular shape with similar external dimensions) is performed based on their flexural stiffness. The upper limit corresponds to the stiffest endoscope currently available on the market, and the lower limit corresponds to the stiffness of pediatric endoscopes defined in [158]. Therefore, the goal is to have a flexible state more flexible than a pediatric endoscope and a rigid state more rigid than the stiffest endoscope. With this target, the controllable stiffness endoscope would have a larger range than the endoscopes on the market now. 


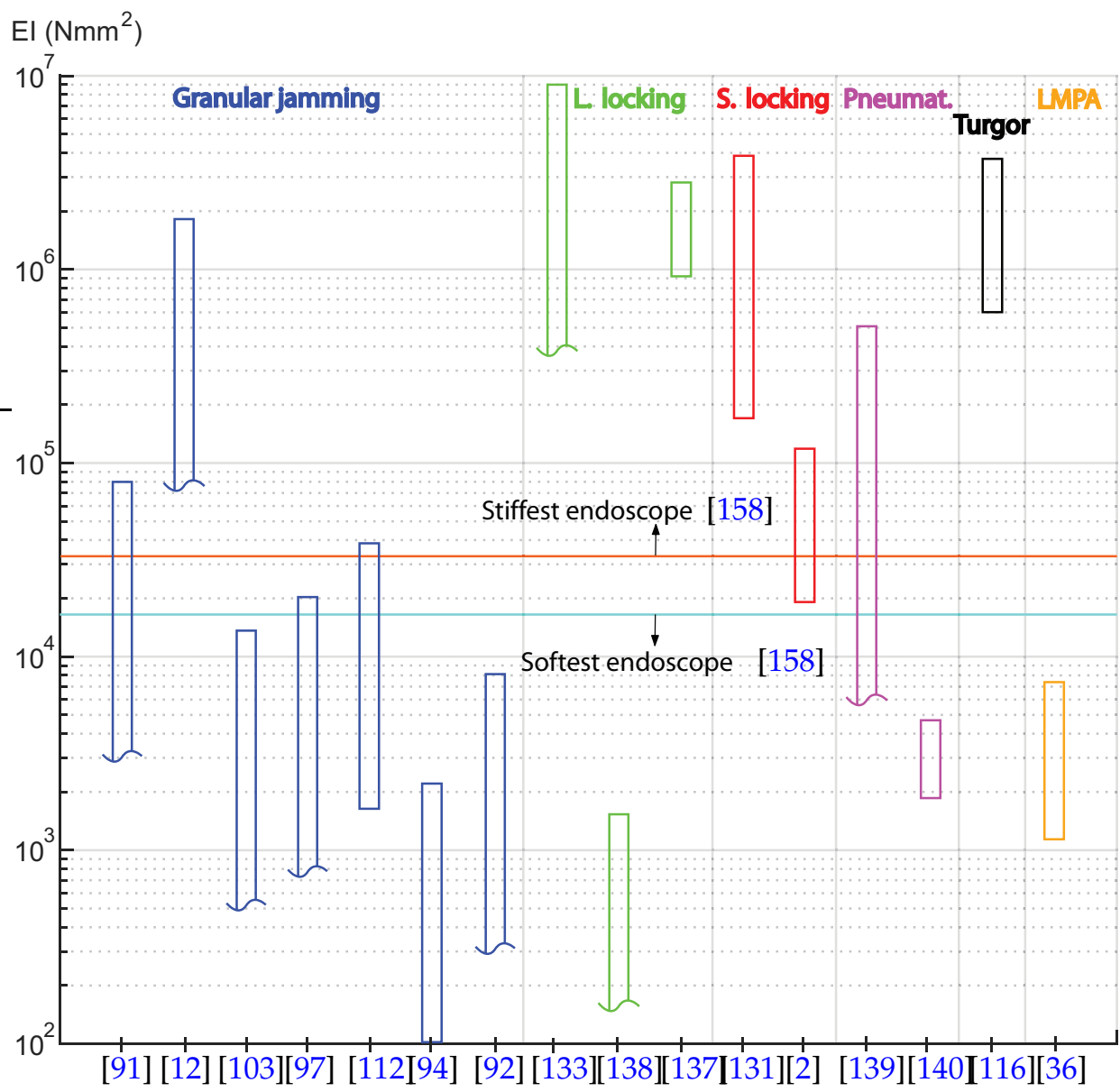

Figure 7. Comparison of various endoscopic-like solutions based on their bending stiffness. The performances of the solutions are compared with current endoscopes. The upper limit of bending stiffness corresponds to the stiffest endoscope on the market, and the lower limit corresponds to the softest one (pediatric type). "L. locking" stands for "Longitudinal locking", "S. locking" for "Segments locking", "Pneumat." for "Pneumatic solutions", "Turgor" for "Turgor pressure" and "LMPA" for "Low Melting Point Alloy".

Granular jamming based on a vacuum gives a stiffness increase proportional to the vacuum applied [98]. The elastic modulus in plant-like structures depends linearly on the turgor pressure [113,114]. In layer jamming based on friction, the force locking the layers depends on the pressure difference (obtained by vacuum) and the contact characteristics (surface, friction and number of sheets) [132,133]. If the friction is too large, the change of stiffness is lower as even with a low pressure difference, the layers are already locked with each other. Some disadvantages of wires tensioning are that the tension has to be high, and therefore, the wires have to be thick; and sufficient space is required for this working principle [132]. The stiffness can be adjusted by the tension of the cables with a quasi-linear relationship [2]. As the tension force can be high, downscaling the segments and wires has therefore limitations [138].

Figure 8 gives design information about material-based solutions. The objectives of pediatric and stiff endoscopes are illustrated for the flexural stiffness. Depending on the dimensions and the material chosen, the flexural stiffness range that can be achieved is illustrated in this graph. These data can help to design a structure for a desired stiffness or to select the material adapted to the dimensional constraints. 


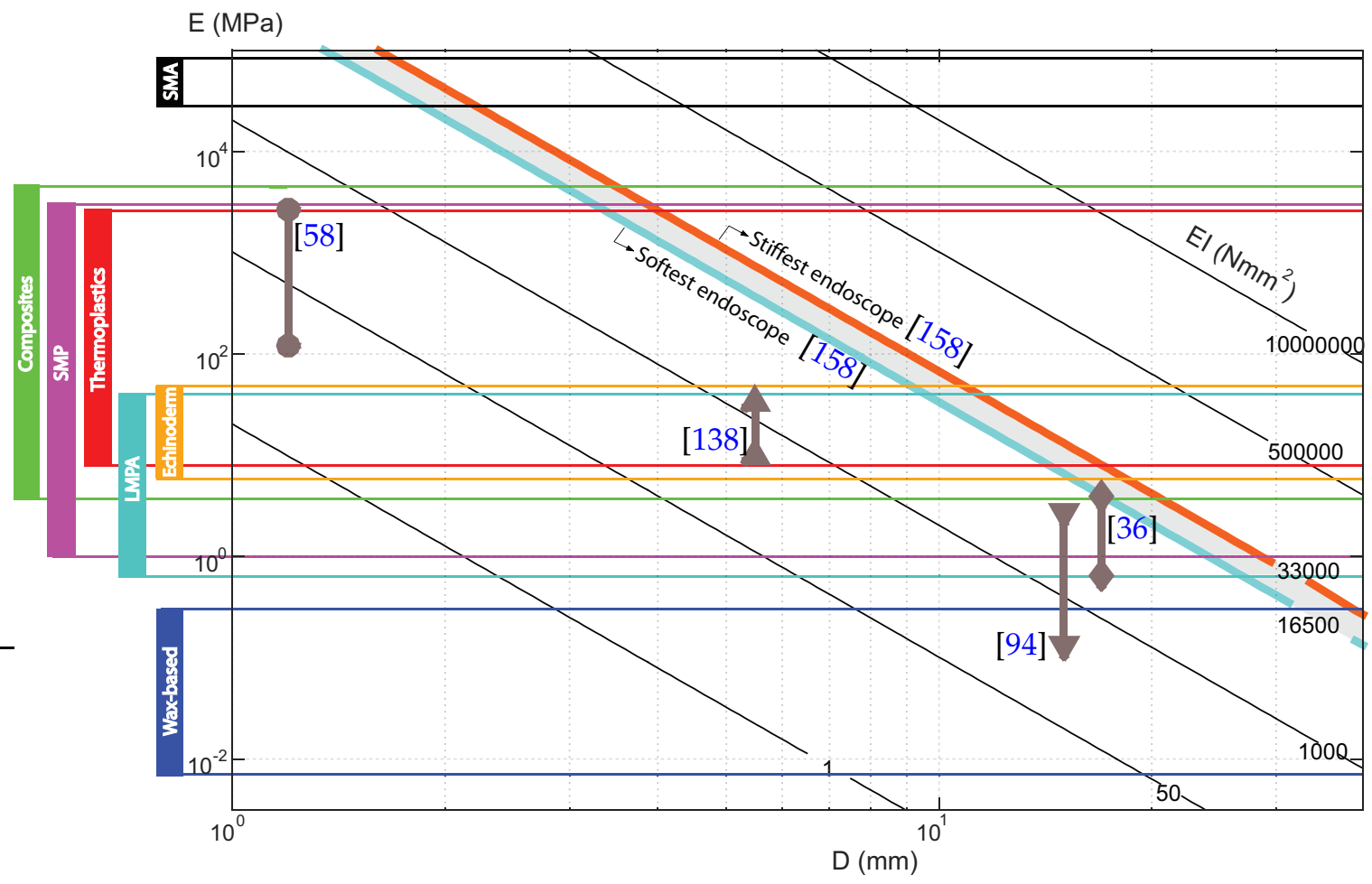

Figure 8. Elastic modulus $(E)$ of material-based solutions compared to an equivalent external diameter $(D)$ and flexural stiffness (EI) (diagonal lines). The objectives of bending stiffness defined by the stiffest and softest endoscopes on the market are the highlighted diagonal lines. Some examples from the literature are represented to illustrate the range of diameters and elastic moduli that have been tested. This graph gives an indication about the material to choose for achieving a given bending stiffness $(E I)$ when an external diameter $(D)$ is imposed, and inversely.

\subsection{Ultimate Force}

The flexural stiffness of the solutions gives their ability to resist external load in an elastic regime. Small deformations are allowed. Nevertheless, the ultimate force or stress is another important parameter. This value will give the maximum loading conditions with which the structure will still function.

The yield stress and the elastic modulus (initial slope of the stress-strain curve) are increasing with the turgor pressure [117]. In layer jamming based on friction, the stiffness is very similar for different vacuum levels, while the ultimate stress is increasing with the pressure [132,133].

The elastic behavior of MR and ER fluids is difficult to evaluate, and the literature gives the yielding stress for both fluids [67-70,72]. MR fluids give higher yield results than ER and can work at lower voltages [66]. The same difficulties are encountered for solder-based solutions for which an ultimate force can be easily measured [45].

\subsection{Activation Time}

The granular jamming has advantages over other tunable stiffness solutions as a fast response (lower than $1 \mathrm{~s}[12,89,98]$ ) and a simple mechanism [112]. The locking of segments by fluid pressurization allows for controlling all of the joints at the same time independently of the shape and gives good activation time performances [135]. In thermal-based solutions, the activation time ranges from less than one second up to minutes [32,38,44,47,58]. Phase-changing materials are suitable for applications with high stiffness, fast and low power locking/unlocking. The wax/hot glue solutions 
take more time to melt and cool down than solder [45]. The change of rheological properties is obtained in a few milliseconds [66,78].

Figure 9 gives a quantitative comparison of the activation times for several solutions. The values often depend on the design, dimensions and stimulus used. For the solutions based on vacuuming and pressure difference, the activation time is related to the amount of air to be removed and to the performances of the pump [107]. The transition between the states can be assumed to be instantaneous for the solutions based on wire tensioning. The solutions involving the change of materials properties show longer activation time, and a proper design may improve their performances.

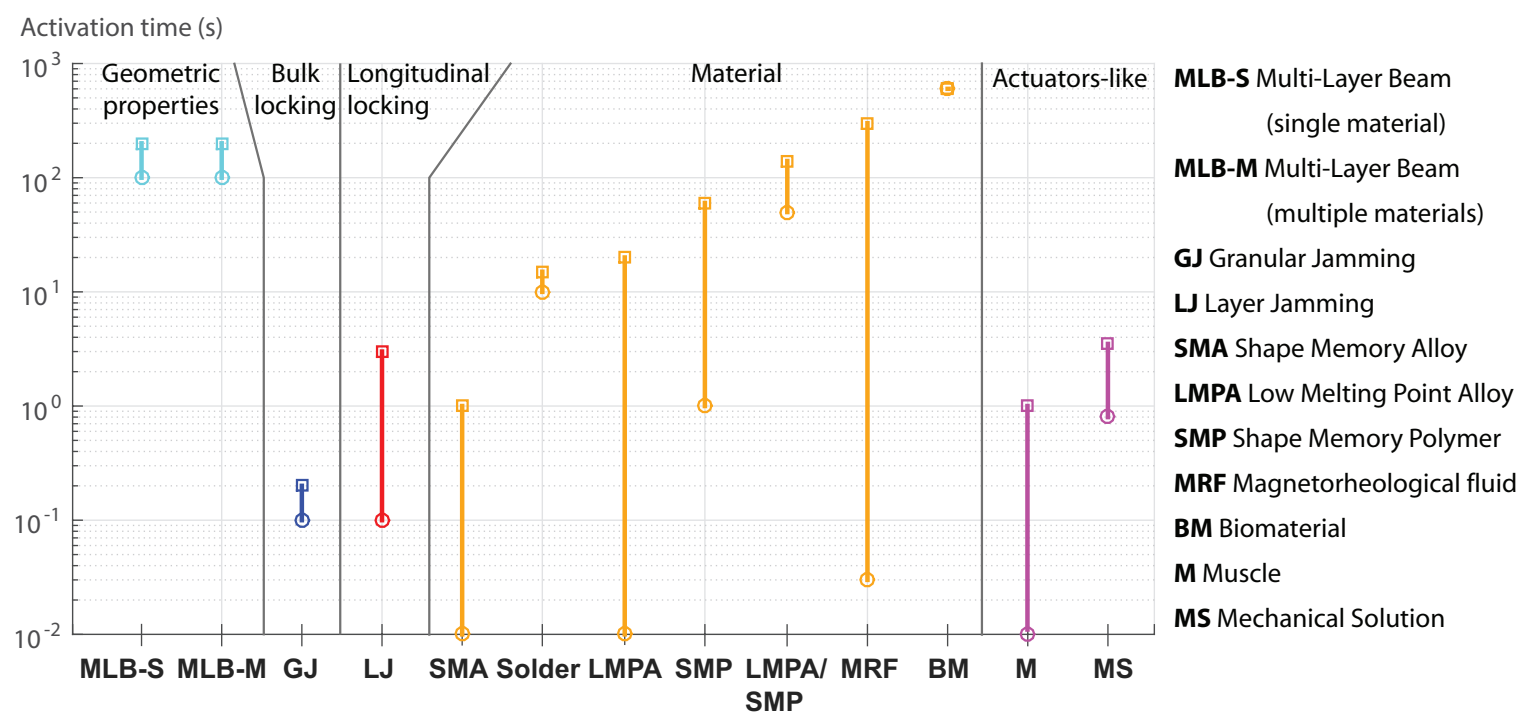

Figure 9. Activation time for several controllable stiffness solutions. The activation time corresponds to the change between the rigid and the flexible states, and inversely. A fast change of stiffness is preferred. The values correspond to averages and depend on the design of the solutions. The biomaterial value corresponds to the skin of echinoderms.

\subsection{Scalability}

Small scale [91] up to large scale [99,101] granular jamming systems have been demonstrated in the literature. Multi-dimensional foldable structures based on granular jamming are presented in [110]. The granular jamming is applicable to many sizes of grippers (from diameters $D_{\text {gripper }}=4 \mathrm{~mm}$ up to $D_{\text {gripper }}=1 \mathrm{~m}$ [87]).

The multi-layer beam solution can easily be scaled. Large design $(45 \mathrm{~cm} \times 152 \mathrm{~cm}$ [24]) also gives good results. As the stiffness change depends on the number of layers, the thickness of the layers will limit the scaling down of the solution. The performances of a prototype based on segments locking with sub-millimeter beads have still to be studied, but scaling down to small beads $(1 \mathrm{~mm} \times 1 \mathrm{~mm})$ has already been validated [122].

\subsection{Medical Requirements}

For medical applications, the temperature that is reached by the device has to be limited. Indeed, the surface of a medical instrument in the human body should not exceed $41^{\circ} \mathrm{C}$ [8]. Heat transmission is required for these solutions. New flexible heaters can be developed. Using a polymer on which a copper layer can adhere would lead to directly embedding electronics on a polymer $[155,165]$.

In [38], two designs of a device based on thermally-activated polymer for stiffness control are proposed. The first consists of a single rod with inner channels containing a thermally-controlled fluid that can transmit heat to change the stiffness of the device. This tube would be placed in the 
endoscope to act on its stiffness. The second solution is an overtube acting similarly, but placed around the endoscope. The working temperatures are $43{ }^{\circ} \mathrm{C}$ for the hot state and $5{ }^{\circ} \mathrm{C}$ for the rigid state. The system is fail-safe, as the human body temperature is used to have a close to flexible state in normal conditions. The required elastic modulus for the extreme temperatures are estimated based on a given design and the flexural stiffness $\left(E_{b} I\right)$ of current endoscopes for a transition temperature $T_{g}$ close to $37^{\circ} \mathrm{C}$. In [69], a change of compliance is observed for small magnetic field (10-35 $\mathrm{mT}$, while other solutions may require a field up to $1 \mathrm{~T})$. Microchannels are filled with MR field; the multiplication of these channels permits a better effect for lower fields and safer working conditions. In solder-based solutions, the Chip Quik solder is chosen as it has a low working temperature and is non-toxic. The joints are heated with strain gauges used as the heater with a flowing current [45].

\section{Applications}

\subsection{Medical Devices}

Several medical instruments in colonoscopy can have benefits of variable stiffness mechanisms to avoid looping. Some are already developed and work properly. The formation of loops is responsible for $90 \%$ of the pain during colonoscopy [166]. An overtube (Shape-Locking Guide-SG-1, by USGI Medical Inc., San Clemente, CA, USA) with variable stiffness capacity can be locked in any configuration, which allows for better support during intervention. Nonetheless, the additional size of the overtube may cause less comfort to the patient [166]. A variable stiffness colonoscope has been developed by Olympus Corporation to avoid the use of stiffening wires or an overtube during interventions requiring a change in stiffness of the device [166].

The challenge for easier and safer endoscopic procedures would be to have a highly flexible endoscope while requiring low support force from the wall of the colon (or other organs) [124]. Several variable stiffness solutions can be applied to endoscopic and/or laparoscopic applications [3,104].

The granular jamming principle based on suction is suitable for medical applications as the system is intrinsically soft and flexible. Furthermore, the use of suction is less dangerous than a source of high pressure in the human body. In 1973, the granular jamming is already used for patient-adaptive splints [108]. Vacuum mattresses, which prevent patients from moving, have been invented by Loeb [167]. The granular jamming can be used in the development of innovative prosthetics [90]. The STIFF-FLOP project proposes to use the granular jamming based on ground coffee material for a stiffening chamber used in laparoscopic soft device $[103,104,106,109]$. The granular jamming is also explored for endoscopic applications with an overtube for colonoscopy in $[96,97]$.

A multi-segment outer sheath for endoscopic interventions is presented in [135]. The "dragon skin"-based endoscope is safe for medical application as it is intrinsically flexible and working with low pressures [134]. Another layer jamming-based tubular solution (targeting endoscopic applications) is proposed in [132,133].

"Multi-layer beam"-based devices can be used in medical sport fields [21]. The multi-layer beam principle can also be applied to adaptive wheelchairs with, for instance, the patented Varstiff device [25].

Several snake-like robots, made of rigid links or beads that can be locked by tensioning a cable, are presented in the literature [2,122,125]. The ShapeLock technology [127-129] is based on a similar locking principle. It is used for improving grasping tasks in endosurgery while giving enough flexibility during the insertion. Similar endoscopic applications can be found in [124]. The ShapeLock mechanism is based on segments locked by wire tensioning to freeze the device in a given configuration and to increase its rigidity [138]. The Highly-Articulated Robotic Probe (HARP) is an endoscopic tool using cable tension to lock its joints and segments $[1,123]$. 
The Aquaplast, Turbocast, Orfit, Watercolors, etc. are medical devices made of thermoplastics that can be used as orthosis and splints [168]. These thermoplastics are heated to be molded to fit the patient's anatomy [168]. Thermoplastics can also be used for developing innovative overtubes [38].

Numerous medical applications of SMA can be found for active-bending guides and catheters. A variable stiffness tool for minimally-invasive surgery is made of a central spring used as a backbone and three SMA wires placed around [53]. Active endoscopes [50], laparoscopic grippers [49], active catheters [52], micro-catheters [169] and neurosurgical robotic structures [51] are examples of the use of SMA in the medical field. SMP can also help in the medical field with needles being softer when heated by contact with the skin or with adaptive devices [54]. SMP are used in other biomedical applications: an SMP-based stent with drug release [170], endovascular devices [171], suturing solutions and implants [56].

In the medical field, a magnetic field can be used to control ablation catheters [172] or guidewires [173]. An MR fluid-based device for leg exoskeleton is presented in [71,74-77]. A knee prosthetic for amputees with an MR fluid-based damper is presented in [80]. An MR fluid damper is also used in the development of active ankle prosthetics [72,174]. An active knee brace is presented in [79] and an MR fluid-based knee prosthesis in [78].

\subsection{Patented Medical Applications}

Granular jamming is applied for example to penile implants and protection systems $[167,175,176]$. The layer jamming is present in various patents [177-179]. Cable tensioning solutions are mainly used for controlling the stiffness of shafts $[178,180,181]$. ER fluids could also be applied to penile implants [182] and medical devices [183]. The use of thermoplastics for medical devices is illustrated in [184-189].

\subsection{Aerospace Engineering}

Reviews for variable stiffness solutions are proposed in the literature for aerospace applications in $[15,190,191]$. In this field, the morphing solutions are applied to adaptive aircraft. This morphing corresponds to shape, area or volume change. These objectives can be achieved by using materials with variable properties or mechanical adaptive structures [191]. This field of applications is really challenging and presents currently a high interest for improving the aircraft performances [190].

\subsection{Soft Robotics}

In the field of soft robotics, soft robots can have rigid links, but they can have soft interactions with their environment thanks to an adaptive control. Another class of robots is made of soft materials with, sometimes, stiffness control to interact with their environment. The main technologies reported for soft robots are Shape Memory Alloys (SMA), Shape Memory Polymers (SMP), Electro-Active Polymers (EAP), fluidic actuators, cable-driven solutions, rheological fluids and granular jamming [192]. A review of active stiffening methods for soft robotic applications, based on mechanical properties change without motion, is proposed in [14]. Reviews for variable stiffness solutions are proposed in the literature for soft robotics [14].

The granular jamming principle is applied to develop universal grippers [85-87,112], user interfaces [107] and finger-based grippers [112]. In [12,89], a robotic arm uses the granular jamming with ground coffee as the granular material in combination with tensioning wires to increase the stiffness of the structure. A multi-segment snake-like robot is developed in [93], while a bellows-shaped structure is presented in [95]. The solution proposed in [98] uses the granular jamming of Styrofoam particles filling a soft vinyl tube, called Particle Mechanical Constraint (PCM).

Variable stiffness based on multi-layer beams can be applied to wearable robots, to light-weight, flexible and small-sized devices [20]. Thermoplastics can be used for grippers with variable stiffness fingers [39] and for smart innovative robotic structures with enhanced properties [13]. A gripper 
made of small bags filled with MR fluids and coupled to a Kuka robot allows for pick and place operations of multiple objects (typically food) [70].

\subsection{Biomimetics}

A fish-like robot is developed in [193-195]. The trust generated by the caudal fin is modified by modifying its stiffness. A variable stiffness fin based on a variable-effective-length spring is proposed in [150]. The length of a plate spring is modified by displacing a PET plate along the spring. A review of under-water robots using smart actuators, such as SMA or ionic polymer metal composite (IPMC), is proposed in [196].

A variable stiffness solution inspired by armadillo's skin is proposed in [197]. Two mechanisms are proposed: sliding and folding mechanisms for multi-layer structures. The sliding mechanism consists of sliding rigid elements to lock the possible motion of the structure. The stiffness of the structure is therefore controlled by the stiffness of the rigid parts. The folding solution is based on folding a structure with rigid patterns on a soft surface.

\subsection{Other Applications}

Granular jamming can be applied in soft robotics (moving robot, gripper, artificial muscle, prosthesis, highly-articulated robot, user interfaces), architecture (large customizable structures, tunable molds, vacuumed bridge, "aggregate architecture"), dynamic application (acoustic absorption, vibration attenuation), etc. [88].

Applications of Vacuumatics can be found in innovative architecture, robotics, biomedical, etc. [100]. The initial concept of Vacuumatics had been introduced in 1971 by John Gilbert, followed by research by Frei Otto [110]. Foldable structures can be improved with granular jamming: a flexible hinge is designed such that it can be stiffened based on the granular jamming principle, locking the folded structure in a given configuration [110].

Applications of multi-layer beams made of multiple materials can be found in active prosthetics, civil engineering with building materials, active damping of vibrations and deformable materials [28].

A solution based on an endoskeleton-like structure may be applied to several variable stiffness robotic application, as for example a fish-like robot [131].

SMA can be used in vibration attenuation [198], an actuator combined with a spring [48], etc. SMG can be used for soft gripping tools [61,62], smart lenses [63] and smart buttons [64].

A Shape Memory Composites (SMC) combining SMA and SMP are proposed in [58] to create fabrics with tunable stiffness. In [199], the combination of SMA and a wire-tensioning solution is proposed. A multi-segmented endoscopic tool can be actuated by tensioning of Nitinol wires.

Applications of MR fluids are mainly used for vibration damping (from vehicle seat suspensions to attenuation of seismic vibrations of structures) [65].

\section{Perspectives and Conclusions}

This review gives an indication about several mechanisms and solutions that can be used for controllable stiffness and shape-locking devices. Depending on the targeted application, the requirement about stiffness gain, stiffness range or activation time may differ. The quantitative comparison based on several criteria selected for medical applications proposed in this work can help to select the most appropriate solution. A qualitative comparison takes place when the literature provides no quantitative data or when parameters cannot be quantified. The classification highlights the mechanism and properties on which the variable stiffness solutions are based. This classification can be helpful for developing new innovative solutions based on hybrid structures or new mechanisms.

Many questions remain about the fabrication of devices, the model of principles and the miniaturization of solutions. The membrane used in vacuumed or pressurized solutions has to 
be sufficiently strong to overtake the stress, but thin and flexible to minimize its influence on the device stiffness. Producing such membranes made of deformable and very thin material is still challenging. It is possible to fabricate them by dip molding, silicone molding, rolling and welding, blow molding, etc. The choice of material is critical, and these methods have limitations and give various performances. The model of the solutions depends on the fabrication of the structures, their working principle and the stimulus used. Experimental data are often easily available, but physical interpretation is not always easy, as for instance for the granular jamming solution (still deeply studied in fundamental research). Finally, the miniaturization of these solutions for small-scale applications is one of the most important challenge. The scaling laws have to be studied and determined for an efficient design. The requirements and specifications have to be defined, and the manufacturing of the structures may be more difficult.

Acknowledgments: This work was supported by the F.N.R.S. (Fonds National de la Recherche Scientifique) through an F.R.I.A. (Fonds pour la formation à la Recherche dans l'Industrie et dans l'Agriculture) grant and a Research Project PDR T1002.14. This project was partially funded by an F.E.R. (Fonds d'Encouragement à la Recherche) funding provided by the Université Libre de Bruxelles. The authors would like to acknowledge the PREDICTION A.R.C. (Actions de Recherche Concertée) project between Université Libre de Bruxelles and Université de Mons for support during this research. This work has been also supported by the Interuniversity Attraction Poles program under grant IAP 7/38 MicroMAST funded by the Belgian Science Policy Office. A special thank you is addressed to Loïc Tadrist for advice about turgor pressure.

Conflicts of Interest: The authors declare no conflict of interest.

\section{Appendix A. Flexural Stiffness of Endoscopes}

The elastic modulus (also called Young's modulus E) corresponds to the linear slope in the stress-strain curve (for tensile, compression or bending testing) [16]. Several definitions exist, but in this work, the initial slope of the stress-strain curve is used. This characteristic corresponds to the elastic behavior of the material. The elastic modulus is a proper parameter to evaluate the stiffness of materials [200]. The elastic modulus of classical robotic material (metals and plastics) is larger than $10^{9} \mathrm{~Pa}$, while for biological tissues and soft materials, the modulus ranges between $10^{2} \mathrm{~Pa}$ and $10^{6} \mathrm{~Pa}$ [41]. Soft robots have stiffness close to biological ones, which makes them safe for human interactions. One of the challenges of soft robotics would be to develop actuators able to tune their shape and stiffness (similarly to muscle tissues).

The flexural stiffness of several endoscopes has been measured and studied in the literature and is compiled in the summary Table A1. Notice that the stiffness of medical device is not constant on the whole length of the device. The range of stiffness is specified if it has been measured for various positions on the scope, otherwise an average is given. Not all the information is provided for all the results.

In 1984, a first effort to quantify the stiffness of endoscopes (from Olympus, Japan and ACM, USA) has been performed by Nemirosvkii and Kuz'Min [201]. A lateral force implied a deflection of the endoscopes, but Wehrmeyer et al. estimated that it did not correspond to actual situation of use of endoscopes [158]. The latter authors claimed that the flexural stiffness had to be evaluated on its buckling performances as the clinical procedures are closer to column buckling as given by Equation (A1) (even if beam bending should give similar results). The bending beam theory is used to evaluate the flexural stiffness by bending of a beam clamped on both sides, with non-rotating supports (called "fixed beam bending" in our work), as given in Equation (A2) [16,202].

$$
E I=\frac{F_{c} L^{2}}{4 \pi^{2}},
$$

where $E I$ is the flexural stiffness, $F_{c}$ is the critical force causing buckling and $L$ is the sample length.

$$
E I=\frac{F_{b} L_{s}^{3}}{192 \delta^{\prime}}
$$


where $E I$ is the flexural stiffness, $F_{b}$ is the bending force, $L_{s}$ is the support span length and $\delta$ is the deflection.

The typical range of stiffness of these endoscopes is $160-240 \mathrm{~N} \mathrm{~cm}^{2}$ [158].

Brooker et al. [5] compared a classical colonoscope (Olympus CF200HL) and a variable stiffness colonoscope (XCF-SH230L) with three-point bending tests with free rotation supports (for which the flexural stiffness is calculated from Equation (A3)). The variable stiffness is obtained by compressing or releasing a metallic helical coil, and allows for lower intervention duration and pain caused to the patient. The same bending test is used in [203] to evaluate the flexural stiffness of its colonoscope.

$$
E I=\frac{F_{b} L_{s}^{3}}{48 \delta}
$$

where $E I$ is the flexural stiffness, $F_{b}$ is the bending force, $L_{s}$ is the support span length and $\delta$ is the deflection.

Bell and Burn [204] compared the results of [5] to other colonoscopes, using the fixed beam bending with a flexural stiffness given in Equation (A2).

In [4], the flexural and torsional stiffness of colonoscopes have been measured for different working temperatures. A reduction of $17 \%$ of the flexural stiffness is observed between $24{ }^{\circ} \mathrm{C}$ and $37^{\circ} \mathrm{C}$. In $[205,206]$, the flexural stiffness of a colonoscope has been measured to $900 \mathrm{~N} \mathrm{~cm}^{2}$ at $20{ }^{\circ} \mathrm{C}$ and to $540 \mathrm{~N} \mathrm{~cm}^{2}$ at $40{ }^{\circ} \mathrm{C}$.

In [207], the author exposes the problem of stiffening colonoscopes. Difficulties encountered during colonoscopies are due to loops in the sigmoid when using flexible colonoscopes. Some endoscopists uses therefore forceps to stiffen their device. The idea of a variable stiffness devices (with several levels of stiffness) is introduced. A prototype of stiffening device the SVSC-1 (Wilson-Cook Medical Inc., Winston-Salem, NC, USA) through an Olympus colonoscope has been used in 25 patients. The stiffening device helped the procedure to decrease the duration of the interventions. Stiffening devices may be used in other interventions: pylorus intubation, other structures intubations in gastro-enterology (choledochoscopy, stenting, etc.). 
Table A1. Compilation of endoscopic stiffness measured in the literature for several type of endoscopic devices $(c=$ colonoscope, $\mathrm{cf}=$ colonofibroscope, $\mathrm{gf}=$ gastrofibroscope). Various bending test methods have been implemented (3pb = three-point bending, $\mathrm{b}=\mathrm{buckling}$, fbb $=\mathrm{fixed}$ beam bending). “VS" stands for "Variable Stiffness device", "avg" for "global average", "avg range" for "average over the minimal and maximal values".

\begin{tabular}{|c|c|c|c|c|c|c|c|c|c|c|c|c|}
\hline$\#$ & Ref & Type & Brand & Type & $\begin{array}{l}D_{\text {out }} \\
\mathrm{mm}\end{array}$ & $\begin{array}{c}\mathrm{L} \\
\mathbf{c m}\end{array}$ & $\begin{array}{c}E I \\
(\text { Avg) } \\
\mathrm{N} \mathrm{cm}^{2}\end{array}$ & $\begin{array}{c}E I \\
\left(\mathrm{Min}^{2}\right) \\
\mathrm{N} \mathrm{cm}^{2}\end{array}$ & $\begin{array}{c}E I \\
(\mathrm{Max}) \\
\mathrm{N} \mathrm{cm}^{2}\end{array}$ & $\begin{array}{c}E I \\
\text { (Avg Range) } \\
\mathrm{N} \mathrm{cm}^{2}\end{array}$ & $\begin{array}{l}\text { Testing } \\
\text { Method }\end{array}$ & Remarks \\
\hline 1 & \multirow{9}{*}{ [158] } & C & Pentax & EC-3800TL (1) & & & 165 & 164.19 & 216.13 & 190.16 & $\mathrm{~b}$ & no stiffener \\
\hline 2 & & c & Pentax & EC-3800TL (1) & & & 215 & & & & $\mathrm{~b}$ & with stiffener \\
\hline 3 & & c & Pentax & EC-3800TL (2) & & & 170 & 173.23 & 250.00 & 211.61 & $b$ & no stiffener \\
\hline 4 & & c & Pentax & EC-3800TL (2) & & & 250 & 227.42 & 330.65 & 279.03 & $b$ & with stiffener \\
\hline 5 & & c & Olympus & CF-100TI & & & 185 & 182.00 & 225.00 & 203.50 & $\mathrm{~b}$ & no stiffener \\
\hline 6 & & c & Olympus & CF-100TI & & & 200 & 210.00 & 259.27 & 234.64 & $\mathrm{~b}$ & with stiffener \\
\hline 7 & & c & Olympus & CF-P20L & & & 200 & 180.00 & 220.00 & 200.00 & $\mathrm{~b}$ & no stiffener \\
\hline 8 & & c & Olympus & CF-100L (1) & & & & 210.00 & 220.00 & 215.00 & $\mathrm{~b}$ & \\
\hline 9 & & c & Olympus & CF-100L (2) & & & & 180.00 & 225.00 & 202.50 & $\mathrm{~b}$ & \\
\hline 10 & \multirow{4}{*}{ [5] } & C & Olympus & XCF-SH230L & 12.9 & 168 & & 70.33 & 264.65 & 167.49 & $3 \mathrm{pb}$ & VS flexible \\
\hline 11 & & c & Olympus & XCF-SH230L & 12.9 & 168 & & 93.53 & 316.12 & 204.83 & $3 \mathrm{pb}$ & VS rigid \\
\hline 12 & & c & Olympus & CF200HL & 13.3 & 165 & & 70.33 & 421.26 & 245.79 & $3 \mathrm{pb}$ & \\
\hline 13 & & c & Olympus & PCF230 & 11.3 & 130 & & 59.45 & 237.09 & 148.27 & $3 \mathrm{pb}$ & Pediatric \\
\hline 14 & \multirow{4}{*}{ [204] } & $\mathrm{C}$ & Olympus & PCF2401 & 11.2 & & & 117.46 & 201,00 & 159.23 & $\mathrm{fbb}$ & \\
\hline 15 & & c & Olympus & CF20HL & 13.3 & & & 210.97 & 522.69 & 366.83 & $\mathrm{fbb}$ & \\
\hline 16 & & c & Olympus & CF-240AL & 12 & & & 103.74 & 425.44 & 264.59 & $\mathrm{fbb}$ & VS flexible \\
\hline 17 & & c & Olympus & CF-240AL & 12 & & & 164.84 & 609.98 & 387.41 & $\mathrm{fbb}$ & VS stiff \\
\hline 18 & \multirow{2}{*}{ [4] } & c & Olympus & CF140S & 13.3 & & & 260.00 & 400.00 & 330.00 & $3 \mathrm{pb}$ & at $24^{\circ} \mathrm{C}$ \\
\hline 19 & & c & Olympus & CF140S & 13.3 & & & 225.00 & 375.00 & 300.00 & $3 \mathrm{pb}$ & at $37^{\circ} \mathrm{C}$ \\
\hline 20 & \multirow{5}{*}{ [201] } & cf & Olympus & single-channel & & & & 71.46 & 118.69 & 95.07 & $\mathrm{fbb}$ & \\
\hline 21 & & $\mathrm{cf}$ & Olympus & two-channels & & & & 82.36 & 155.02 & 118.69 & $\mathrm{fbb}$ & \\
\hline 22 & & $\mathrm{cf}$ & $\mathrm{ACM}$ & two-channels & & & & 249.49 & 283.40 & 266.44 & $\mathrm{fbb}$ & \\
\hline 23 & & c & $\mathrm{ACM}$ & single-channel & & & & 71.46 & 405.72 & 238.59 & $\mathrm{fbb}$ & \\
\hline 24 & & gf & Olympus & single-channel & & & & 81.14 & 164.71 & 122.93 & $\mathrm{fbb}$ & \\
\hline 25 & [203] & $\mathrm{C}$ & Olympus & CF-Q160L & & & & 274.50 & 655.96 & 465.23 & $3 \mathrm{pb}$ & \\
\hline 26 & \multirow{2}{*}{ [205] } & $\mathrm{C}$ & & & & & 900 & & & & $\mathrm{fbb}$ & at $20^{\circ} \mathrm{C}$ \\
\hline 27 & & c & & & & & 540 & & & & $\mathrm{fbb}$ & at $40^{\circ} \mathrm{C}$ \\
\hline
\end{tabular}




\section{References}

1. Degani, A.; Choset, H.; Wolf, A.; Ota, T.; Zenati, M.A. Percutaneous intrapericardial interventions using a highly articulated robotic probe. In Proceedings of the First IEEE/RAS-EMBS International Conference on Biomedical Robotics and Biomechatronics, Pisa, Italy, 20-22 February 2006; pp. 7-12.

2. Kim, Y.J.; Cheng, S.; Kim, S.; Iagnemma, K. A stiffness-adjustable hyperredundant manipulator using a variable neutral-line mechanism for minimally invasive surgery. IEEE Trans. Robot. 2014, 30, 382-395.

3. Loeve, A.; Breedveld, P.; Dankelman, J. Scopes too flexible... and too stiff. IEEE Pulse 2010, 1, $26-41$.

4. Hellier, D.; Albermani, F.; Evans, B.; De Visser, H.; Adam, C.; Passenger, J. Flexural and torsional rigidity of colonoscopes at room and body temperatures. Proc. Inst. Mech. Eng. Part H J. Eng. Med. 2011, 225, 389-399.

5. Brooker, J.; Saunders, B.; Shah, S.; Williams, C. A new variable stiffness colonoscope makes colonoscopy easier: A randomised controlled trial. Gut 2000, 46, 801-805.

6. Park, S.; Cha, K.; Park, J. Development of biomedical microrobot for intravascular therapy. Int. J. Adv. Robot. Syst. 2010, 7, 1.

7. Kinoshita, I.; Katoh, O.; Nariyama, J.; Otsuji, S.; Tateyama, H.; Kobayashi, T.; Shibata, N.; Ishihara, T.; Ohsawa, N. Coronary angioplasty of chronic total occlusions with bridging collateral vessels: Immediate and follow-up outcome from a large single-center experience. J. Am. Coll. Cardiol. 1995, 26, 409-415.

8. Haga, Y.; Mineta, T.; Makishi, W.; Matsunaga, T.; Esashi, M. Active bending catheter and endoscope using shape memory alloy actuators. In Shape Memory Alloys; Cismasiu, C., Ed.; InTech: Rijeka, Croatia, 2010; pp. 107-126, ISBN: 978-953-307-106-0.

9. Qaiser, Z.; Kang, L.; Johnson, S. Design of a bioinspired tunable stiffness robotic foot. Mech. Mach. Theory 2017, 110, 1-15.

10. Liu, Y.; Matsuhisa, H.; Utsuno, H. Semi-active vibration isolation system with variable stiffness and damping control. J. Sound Vib. 2008, 313, 16-28.

11. Fan, X.; Zhu, L.; Wang, K.; Wang, B.; Wu, Y.; Xie, W.; Huang, C.; Chan, B.P.; Du, Y. Stiffness-Controlled Thermoresponsive Hydrogels for Cell Harvesting with Sustained Mechanical Memory. Adv. Healthc. Mater. 2017, 6, doi:10.1002/adhm.201601152.

12. Cheng, N.G.; Lobovsky, M.B.; Keating, S.J.; Setapen, A.M.; Gero, K.I.; Hosoi, A.E.; Iagnemma, K.D. Design and analysis of a robust, low-cost, highly articulated manipulator enabled by jamming of granular media. In Proceedings of the 2012 IEEE International Conference on Robotics and Automation (ICRA), Saint Paul, MN, USA, 14-18 May 2012; pp. 4328-4333.

13. McEvoy, M.A.; Correll, N. Thermoplastic variable stiffness composites with embedded, networked sensing, actuation, and control. J. Compos. Mater. 2015, 49, 1799-1808.

14. Manti, M.; Cacucciolo, V.; Cianchetti, M. Stiffening in soft robotics: A review of the state of the art. IEEE Robot. Autom. Mag. 2016, 23, 93-106.

15. Kuder, I.K.; Arrieta, A.F.; Raither, W.E.; Ermanni, P. Variable stiffness material and structural concepts for morphing applications. Prog. Aerosp. Sci. 2013, 63, 33-55.

16. Gere, J.M.; Goodno, B.J. Mechanics of Materials, 7th ed.; Cengage Learning: Boston, MA, USA, 2009.

17. Hayes, G.J.; Liu, Y.; Genzer, J.; Lazzi, G.; Dickey, M.D. Self-folding origami microstrip antennas. IEEE Trans. Antennas Propag. 2014, 62, 5416-5419.

18. Henry, C.; McKnight, G. Cellular variable stiffness materials for ultra-large reversible deformations in reconfigurable structures. Proc. SPIE 2006, 6170, 617023.

19. Krishnan, G.; Bishop-Moser, J.; Kim, C.; Kota, S. Kinematics of a generalized class of pneumatic artificial muscles. J. Mech. Robot. 2015, 7, 041014.

20. Kawamura, S.; Yamamoto, T.; Ishida, D.; Ogata, T.; Nakayama, Y.; Tabata, O.; Sugiyama, S. Development of passive elements with variable mechanical impedance for wearable robots. In Proceedings of the IEEE International Conference on Robotics and Automation, Washington, DC, USA, 11-15 May 2002; pp. 248-253.

21. Tabata, O.; Konishi, S.; Cusin, P.; Ito, Y.; Kawai, F.; Hirai, S.; Kawamura, S. Micro fabricated tunable bending stiffness devices. Sens. Actuators A Phys. 2001, 89, 119-123.

22. Henke, M.; Gerlach, G. On a high-potential variable-stiffness device. Microsyst. Technol. 2014, 20, 599-606.

23. Henke, M.; Gerlach, G. A multi-layered variable stiffness device based on smart form closure actuators. J. Intell. Mater. Syst. Struct. 2016, 27, 375-383. 
24. Ou, J.; Yao, L.; Tauber, D.; Steimle, J.; Niiyama, R.; Ishii, H. JamSheets: Thin interfaces with tunable stiffness enabled by layer jamming. In Proceedings of the 8th International Conference on Tangible, Embedded and Embodied Interaction, Munich, Germany, 16-19 February 2014; pp. 65-72.

25. Veneman, J.; Manterola, I.; Bureau, M.; Jung, J.H. Varstiff, An Innovative Variable Stiffness Material, Applied in a Wheelchair Positioning Device. Available online: https://www.ige.tu-berlin.de/fileadm in/fg176/IGE_Printreihe/TAR_2015/Session_order/Postersession_Event_6_paper_Veneman_Jan_.pdf (accessed on 3 July 2017).

26. Gandhi, F.; Kang, S.G. Beams with controllable flexural stiffness. Smart Mater. Struct. 2007, 16, 1179.

27. Mcknight, G.; Doty, R.; Keefe, A.; Herrera, G.; Henry, C. Segmented reinforcement variable stiffness materials for reconfigurable surfaces. J. Intell. Mater. Syst. Struct. 2010, 21, 1783-1793.

28. Bergamini, A. Electrostatic Modification of the Bending Stiffness of Adaptive Structures. Ph.D. Thesis, ETH Zurich, Zurich, Switzerland, 2009.

29. Murray, G.; Gandhi, F.; Kang, S.G. Flexural stiffness control of multilayered beams. AIAA J. 2009, 47, 757-766.

30. Murray, G.; Gandhi, F. Multi-layered controllable stiffness beams for morphing: Energy, actuation force, and material strain considerations. Smart Mater. Struct. 2010, 19, 045002.

31. Natterer, J.; Weinand, Y. Modeling of multi-layer beam with interlayer slips. In Proceedings of the 10th World Conference on Timber Engineering (WCTE), 2008, Miyazaki, Japan, 2-5 June 2008.

32. Shan, W.; Lu, T.; Majidi, C. Soft-matter composites with electrically tunable elastic rigidity. Smart Mater. Struct. 2013, 22, 085005.

33. Shan, W.; Lu, T.; Wang, Z.; Majidi, C. Thermal analysis and design of a multi-layered rigidity tunable composite. Int. J. Heat Mass Transf. 2013, 66, 271-278.

34. Schubert, B.E.; Floreano, D. Variable stiffness material based on rigid low-melting-point-alloy microstructures embedded in soft poly(dimethylsiloxane) (PDMS). Rsc Adv. 2013, 3, 24671-24679.

35. Shintake, J.; Schubert, B.; Rosset, S.; Shea, H.; Floreano, D. Variable stiffness actuator for soft robotics using dielectric elastomer and low-melting-point alloy. In Proceedings of the 2015 IEEE/RSJ International Conference on Intelligent Robots and Systems (IROS), Hamburg, Germany, 28 September-2 October 2015; pp. 1097-1102.

36. Zhao, R.; Yao, Y.; Luo, Y. Development of a Variable Stiffness Over Tube Based on Low-Melting-Point-Alloy for Endoscopic Surgery. J. Med. Dev. 2016, 10, 021002.

37. Zheng, L.; Yoshida, S.; Morimoto, Y.; Onoe, H.; Takeuchi, S. Pneumatic balloon actuator with tunable bending points. In Proceedings of the 2015 28th IEEE International Conference on Micro Electro Mechanical Systems (MEMS), Estoril, Portugal, 18-22 January 2015; pp. 18-21.

38. Loeve, A.J.; Bosma, J.H.; Breedveld, P.; Dodou, D.; Dankelman, J. Polymer rigidity control for endoscopic shaft-guide "Plastolock"—A feasibility study. J. Med. Dev. 2010, 4, 045001.

39. Balasubramanian, A.; Standish, M.; Bettinger, C.J. Microfluidic thermally activated materials for rapid control of macroscopic compliance. Adv. Funct. Mater. 2014, 24, 4860-4866.

40. McEvoy, M.; Correll, N. Shape change through programmable stiffness. In Experimental Robotics; Springer: Hamburg, Germany, 2016; pp. 893-907.

41. Shan, W.; Diller, S.; Tutcuoglu, A.; Majidi, C. Rigidity-tuning conductive elastomer. Smart Mater. Struct. 2015, 24, 065001.

42. Cheng, N.G. Design and Analysis of Active Fluid-and-Cellular Solid Composites for Controllable Stiffness Robotic Elements. Ph.D. Thesis, Massachusetts Institute of Technology, Cambridge, MA, USA, 2009.

43. Cheng, N.G.; Gopinath, A.; Wang, L.; Iagnemma, K.; Hosoi, A.E. Thermally Tunable, Self-Healing Composites for Soft Robotic Applications. Macromol. Mater. Eng. 2014, 299, 1279-1284.

44. Cheng, N.; Ishigami, G.; Hawthorne, S.; Chen, H.; Hansen, M.; Telleria, M.; Playter, R.; Iagnemma, K. Design and analysis of a soft mobile robot composed of multiple thermally activated joints driven by a single actuator. In Proceedings of the 2010 IEEE International Conference on Robotics and Automation (ICRA), Anchorage, AK, USA , 3-7 May 2010; pp. 5207-5212.

45. Telleria, M.J.; Hansen, M.; Campbell, D.; Servi, A.; Culpepper, M.L. Modeling and implementation of solder-activated joints for single-actuator, centimeter-scale robotic mechanisms. In Proceedings of the 2010 IEEE International Conference on Robotics and Automation (ICRA), Anchorage, AK, USA, 3-7 May 2010; pp. 1681-1686. 
46. Hodgson, D.E.; Ming, W.; Biermann, R.J. Shape memory alloys. ASM Int. Met. Handb. Tenth Ed. 1990, 2, 897-902.

47. Liu, C.; Qin, H.; Mather, P. Review of progress in shape-memory polymers. J. Mater. Chem. 2007, 17, 1543-1558.

48. Swensen, J.P.; Dollar, A.M. Optimization of parallel spring antagonists for Nitinol shape memory alloy actuators. In Proceedings of the 2014 IEEE International Conference on Robotics and Automation (ICRA), Hong Kong, China, 31 May-7 June 2014; pp. 6345-6349.

49. Kianzad, S.; Amini, A.; Karkouti, S.O. Force control of laparoscopy grasper using antagonistic shape memory alloy. In Proceedings of the 2011 1st Middle East Conference on Biomedical Engineering (MECBME), Sharjah, United Arab Emirates, 21-24 February 2011; pp. 335-338.

50. Ikuta, K.; Tsukamoto, M.; Hirose, S. Shape memory alloy servo actuator system with electric resistance feedback and application for active endoscope. In Proceedings of the 1988 IEEE International Conference on Robotics and Automation, Philadelphia, PA, USA, 24-29 April 1988; pp. 427-430.

51. Ho, M.; Desai, J.P. Characterization of SMA actuator for applications in robotic neurosurgery. In Proceedings of the Annual International Conference of the Engineering in Medicine and Biology Society, Minneapolis, MN, USA, 3-6 September 2009; pp. 6856-6859.

52. Haga, Y.; Mizushima, M.; Matsunaga, T.; Totsu, K.; Esashi, M. Active bending ileus tube using shape memory alloy for treatment of intestinal obstruction. In Proceedings of the 3rd IEEE/EMBS Special Topic Conference on Microtechnology in Medicine and Biology, Oahu, HI, USA, 12-15 May 2005; pp. 249-252.

53. Arora, A.; Ambe, Y.; Kim, T.H.; Ariizumi, R.; Matsuno, F. Development of a maneuverable flexible manipulator for minimally invasive surgery with varied stiffness. Artifi. Life Robot. 2014, 19, 340-346.

54. SMP Technologies Inc. Intelligent Material Able to Adjust Itself Accordingly to Ensure the Highest Llevel of Comfort \& Affinity with Human Body; Technical Report; SMP Technologies Inc.: Scotts Valley, CA, USA, 2014.

55. Ratna, D.; Karger-Kocsis, J. Recent advances in shape memory polymers and composites: A review. J. Mater. Sci. 2008, 43, 254-269.

56. Lendlein, A.; Langer, R. Biodegradable, elastic shape-memory polymers for potential biomedical applications. Science 2002, 296, 1673-1676.

57. Meng, Q.; Hu, J. A review of shape memory polymer composites and blends. Compos. Part A Appl. Sci. Manuf. 2009, 40, 1661-1672.

58. Chenal, T.P.; Case, J.C.; Paik, J.; Kramer, R.K. Variable stiffness fabrics with embedded shape memory materials for wearable applications. In Proceedings of the 2014 IEEE/RSJ International Conference on Intelligent Robots and Systems (IROS 2014), Chicago, IL, USA, 14-18 September 2014; pp. 2827-2831.

59. Chen, Y.; Sun, J.; Liu, Y.; Leng, J. Variable stiffness property study on shape memory polymer composite tube. Smart Mater. Struct. 2012, 21, 094021.

60. Amano, Y.; Hidema, R.; Gong, J.; Furukawa, H. Creation of Shape-memory Gels with Inter-crosslinking Network Structure. Chem. Lett. 2012, 41, 1029-1031.

61. Yamano, M.; Akiba, N.; Gong, J.; Furukawa, H. Experiments of a two-arm robot using shape memory gel. In Proceedings of the 2012 IEEE/SICE International Symposium on System Integration (SII), Fukuoka, Japan, 16-18 December 2012; pp. 236-241.

62. Yamano, M.; Goto, D.; Ujiie, K.; Akiba, N.; Gong, J.; Furukawa, H.; Tadakuma, R. Experiments of a variable stiffness robot using shape memory gel. In Proceedings of the 2013 IEEE/SICE International Symposium on System Integration (SII), Kobe, Japan, 15-17 December 2013; pp. 647-652.

63. Yokoo, T.; Hidema, R.; Furukawa, H. Smart lenses developed with high-strength and shape memory gels. E-J. Surf. Sci. Nanotechnol. 2012, 10, 243-247.

64. Harada, S.; Hidema, R.; Gong, J.; Furukawa, H. Intelligent Button Developed Using Smart Soft and Wet Materials. Chem. Lett. 2012, 41, 1047-1049.

65. Jolly, M.R.; Bender, J.W.; Carlson, J.D. Properties and applications of commercial magnetorheological fluids. J. Intell. Mater. Syst. Struct. 1999, 10, 5-13.

66. Sadeghi, A.; Beccai, L.; Mazzolai, B. Innovative soft robots based on electro-rheological fluids. In Proceedings of the 2012 IEEE/RSJ International Conference on Intelligent Robots and Systems (IROS), Vilamoura, Portugal, 7-12 October 2012; pp. 4237-4242.

67. Park, G.; Bement, M.T.; Hartman, D.A.; Smith, R.E.; Farrar, C.R. The use of active materials for machining processes: A review. Int. J. Mach. Tools Manuf. 2007, 47, 2189-2206. 
68. Yalcintas, M.; Dai, H. Magnetorheological and electrorheological materials in adaptive structures and their performance comparison. Smart Mater. Struct. 1999, 8, 560.

69. Majidi, C.; Wood, R.J. Tunable elastic stiffness with microconfined magnetorheological domains at low magnetic field. Appl. Phys. Lett. 2010, 97, 164104.

70. Pettersson, A.; Davis, S.; Gray, J.; Dodd, T.; Ohlsson, T. Design of a magnetorheological robot gripper for handling of delicate food products with varying shapes. J. Food Eng. 2010, 98, 332-338.

71. Ma, H.; Chen, B.; Qin, L.; Liao, W.H. Design and testing of a regenerative magnetorheological actuator for assistive knee braces. Smart Mater. Struct. 2017, 26, 035013.

72. Furusho, J.; Kikuchi, T.; Tokuda, M.; Kakehashi, T.; Ikeda, K.; Morimoto, S.; Hashimoto, Y.; Tomiyama, H.; Nakagawa, A.; Akazawa, Y. Development of shear type compact MR brake for the intelligent ankle-foot orthosis and its control; research and development in NEDO for practical application of human support robot. In Proceedings of the IEEE 10th International Conference on Rehabilitation Robotics, Noordwijk, The Netherlands, 13-15 June 2007; pp. 89-94.

73. Wen, W.; Huang, X.; Yang, S.; Lu, K.; Sheng, P. The giant electrorheological effect in suspensions of nanoparticles. Nat. Mater. 2003, 2, 727-730.

74. Chen, J.; Liao, W.H. Development and testing of a magnetorheological actuator for an assistive knee brace. In Proceedings of the the 15th International Symposium on Smart Structures and Materials \& Nondestructive Evaluation and Health Monitoring, San Diego, CA, USA, 9 March 2008.

75. Chen, J.; Liao, W.H. Design and testing of assistive knee brace with magnetorheological actuator. In Proceedings of the IEEE International Conference on Robotics and Biomimetics, Bangkok, Thailand, 22-25 February 2009; pp. 512-517.

76. Chen, J.; Liao, W. Design, testing and control of a magnetorheological actuator for assistive knee braces. Smart Mater. Struct. 2010, 19, 035029.

77. Chen, J.; Liao, W.H. Design and control of a magnetorheological actuator for leg exoskeleton. In Proceedings of the IEEE International Conference on Robotics and Biomimetics, Sanya, China, 15-18 December 2007; pp. 1388-1393.

78. Carlson, J.D.; Matthis, W.; Toscano, J.R. Smart prosthetics based on magnetorheological fluids. In Proceedings of the SPIE's 8th Annual International Symposium on Smart Structures and Materials, Newport Beach, CA, USA, 4 March 2001; pp. 308-316.

79. Ahmadkhanlou, F.; Zite, J.L.; Washington, G.N. A magnetorheological fluid-based controllable active knee brace. In Proceedings of the 14th International Symposium on Smart Structures and Materials \& Nondestructive Evaluation and Health Monitoring, San Diego, CA, USA, 18 March 2007.

80. Herr, H.; Wilkenfeld, A. User-adaptive control of a magnetorheological prosthetic knee. Ind. Robot Int. J. 2003, 30, 42-55.

81. Trotter, J.; Tipper, J.; Lyons-Levy, G.; Chino, K.; Heuer, A.; Liu, Z.; Mrksich, M.; Hodneland, C.; Dillmore, W.S.; Koob, T.; et al. Towards a fibrous composite with dynamically controlled stiffness: Lessons from echinoderms. Biochem. Soc. Trans. 2000, 357-362, doi:10.1042/bst0280357.

82. Shanmuganathan, K.; Capadona, J.R.; Rowan, S.J.; Weder, C. Biomimetic mechanically adaptive nanocomposites. Prog. Polym. Sci. 2010, 35, 212-222.

83. Shanmuganathan, K.; Capadona, J.R.; Rowan, S.J.; Weder, C. Bio-inspired mechanically-adaptive nanocomposites derived from cotton cellulose whiskers. J. Mater. Chem. 2010, 20, 180-186.

84. Capadona, J.R.; Shanmuganathan, K.; Tyler, D.J.; Rowan, S.J.; Weder, C. Stimuli-responsive polymer nanocomposites inspired by the SEA cucumber dermis. Science 2008, 319, 1370-1374.

85. Brown, E.; Rodenberg, N.; Amend, J.; Mozeika, A.; Steltz, E.; Zakin, M.R.; Lipson, H.; Jaeger, H.M. Universal robotic gripper based on the jamming of granular material. Proc. Natl. Acad. Sci. USA 2010, 107, 18809-18814.

86. Amend, J.R.; Brown, E.; Rodenberg, N.; Jaeger, H.M.; Lipson, H. A positive pressure universal gripper based on the jamming of granular material. IEEE Trans. Robot. 2012, 28, 341-350.

87. Amend, J.; Cheng, N.; Fakhouri, S.; Culley, B. Soft Robotics Commercialization: Jamming Grippers from Research to Product. Soft Robot. 2016, 3, 213-222.

88. Jaeger, H.M. Celebrating soft matter's 10th anniversary: Toward jamming by design. Soft Matter 2015, 11, 12-27. 
89. Cheng, N.G. Design and Analysis of Jammable Granular Systems. Ph.D. Thesis, Massachusetts Institute of Technology, Cambridge, MA, USA, 2013.

90. Cheng, N.; Amend, J.; Farrell, T.; Latour, D.; Martinez, C.; Johansson, J.; McNicoll, A.; Wartenberg, M.; Naseef, S.; Hanson, W.; et al. Prosthetic jamming terminal device: A case study of untethered soft robotics. Soft Robot. 2016, 3, 205-212.

91. Loeve, A.J.; van de Ven, O.S.; Vogel, J.G.; Breedveld, P.; Dankelman, J. Vacuum packed particles as flexible endoscope guides with controllable rigidity. Granul. Matter 2010, 12, 543-554.

92. Jiang, A.; Xynogalas, G.; Dasgupta, P.; Althoefer, K.; Nanayakkara, T. Design of a variable stiffness flexible manipulator with composite granular jamming and membrane coupling. In Proceediongs of the 2012 IEEE/RSJ International Conference on Intelligent Robots and Systems (IROS), Vilamoura, Portugal, 7-12 October 2012; pp. 2922-2927.

93. Jiang, A.; Althoefer, K.; Dasgupta, P.; Nanayakkara, T. The Core Snake, the variable stiffness laparoscopic camera. In Proceedings of the Hamlyn Symposium on Medical Robotics, London, UK, 22-25 June 2013.

94. Jiang, A.; Ranzani, T.; Gerboni, G.; Lekstutyte, L.; Althoefer, K.; Dasgupta, P.; Nanayakkara, T. Robotic granular jamming: Does the membrane matter? Soft Robot. 2014, 1, 192-201.

95. Jiang, A.; Adejokun, S.; Faragasso, A.; Althoefer, K.; Nanayakkara, T.; Dasgupta, P. The granular jamming integrated actuator. In Proceedings of the 2014 International Conference on Advanced Robotics and Intelligent Systems (ARIS), Taipei, Taiwan, 6-8 June 2014; pp. 12-17.

96. Yanagida, T.; Adachi, K.; Nakamura, T. Development of endoscopic device to veer out a latex tube with jamming by granular materials. In Proceedings of the 2013 IEEE International Conference on Robotics and Biomimetics (ROBIO), Shenzhen, China, 12-14 December 2013; pp. 1474-1479.

97. Yanagida, T.; Kamagata, T.; Nakamura, T. Development of an Endoscopic Support Device Using Veering-out Tube with Stiffening Capability by Granular Jamming. Trans. Soc. Instrum. Control Eng. 2015, 51, 290-296.

98. Mitsuda, T.; Kuge, S.; Wakabayashi, M.; Kawamura, S. Haptic displays implemented by controllable passive elements. In Proceedings of the IEEE International Conference on Robotics and Automation, Washington, DC, USA, 11-15 May 2002; Volume 4, pp. 4223-4228.

99. Huijben, F.; van Herwijnen, F.; Lindner, G. Vacuumatic pre-stressed flexible architectural structures. In Proceedings of the III International Conference on Textile Composites and Inflatable Structures, Barcelona, Spain, 17-19 September 2007; pp. 197-200.

100. Huijben, F.; Van Herwijnen, F. Vacuumatics; Shaping space by "freezing" the geometry of structures. In Proceedings of the Tectonics Making Meaning Conference, Eindhoven, The Netherlands, 10-12 December 2007.

101. Huijben, F.; Herwijnen, F.V.; Nijsse, R. VACUUMATICS; Systematic Flexural Rigidity Analysis. In Proceedings of the International Association for Shell and Spatial Structures (IASS) Symposium, Shanghai, China, 8-12 November 2010; pp. 8-12.

102. Athanassiadis, A.G.; Miskin, M.Z.; Kaplan, P.; Rodenberg, N.; Lee, S.H.; Merritt, J.; Brown, E.; Amend, J.; Lipson, H.; Jaeger, H.M. Particle shape effects on the stress response of granular packings. Soft Matter 2014, 10, 48-59.

103. Cianchetti, M.; Ranzani, T.; Gerboni, G.; De Falco, I.; Laschi, C.; Menciassi, A. STIFF-FLOP surgical manipulator: Mechanical design and experimental characterization of the single module. In Proceedings of the 2013 IEEE/RSJ International Conference on Intelligent Robots and Systems (IROS), Tokyo, Japan, 3-7 November 2013; pp. 3576-3581.

104. Cianchetti, M.; Ranzani, T.; Gerboni, G.; Nanayakkara, T.; Althoefer, K.; Dasgupta, P.; Menciassi, A. Soft robotics technologies to address shortcomings in today's minimally invasive surgery: The STIFF-FLOP approach. Soft Robot. 2014, 1, 122-131.

105. De Falco, I.; Cianchetti, M.; Menciassi, A. A soft and controllable stiffness manipulator for minimally invasive surgery: Preliminary characterization of the modular design. In Proceedings of the 36th Annual International Conference of the IEEE Engineering in Medicine and Biology Society (EMBC), Chicago, IL, USA, 26-30 August 2014.

106. De Falco, I.; Cianchetti, M.; Menciassi, A. STIFF-FLOP surgical manipulator: Design and preliminary motion evaluation. In Proceedings of the 4th WorkShop on Computer/Robot Assisted Surgery (CRAS), Genoa, Italy, 14-16 October 2014; pp. 131-134. 
107. Follmer, S.; Leithinger, D.; Olwal, A.; Cheng, N.; Ishii, H. Jamming user interfaces: Programmable particle stiffness and sensing for malleable and shape-changing devices. In Proceedings of the 25th Annual ACM Symposium on User Interface Software and Technology, Cambridge, MA, USA, 7-10 October 2012; pp. 519-528.

108. Letts, R.; Hobson, D. The vacuum splint: An aid in emergency splinting of fractures. Can. Med. Assoc. J. 1973, 109, 599.

109. Mustaza, S.M.; Mahdi, D.; Saaj, C.; Albukhanajer, W.A.; Lekakou, C.; Elsayed, Y.; Fras, J. Tuneable Stiffness Design of Soft Continuum Manipulator. In Proceedings of the International Conference on Intelligent Robotics and Applications, Portsmouth, UK, 24-27 August 2015; pp. 152-163.

110. Tachi, T.; Masubuchi, M.; Iwamoto, M. Rigid Origami Structures with Vacuumatics: Geometric Considerations. In Proceedings of the IASS-APCS 2012, Seoul, Korea, 21-24 May 2012.

111. Wall, V.; Deimel, R.; Brock, O. Selective stiffening of soft actuators based on jamming. In Proceedings of the 2015 IEEE International Conference on Robotics and Automation (ICRA), Seattle, WA, USA, 26-30 May 2015; pp. 252-257.

112. Wei, Y.; Chen, Y.; Ren, T.; Chen, Q.; Yan, C.; Yang, Y.; Li, Y. A Novel, Variable Stiffness Robotic Gripper Based on Integrated Soft Actuating and Particle Jamming. Soft Robot. 2016, 3, 134-143.

113. Nilsson, S.B.; Hertz, C.H.; Falk, S. On the Relation between Turgor Pressure and Tissue Rigidity. II. Theoretical Calculations on Model Systems Physiol. Plant. 1958, 11, 818-837.

114. Falk, S.; Hertz, C.H.; Virgin, H.I. On the Relation between Turgor Pressure and Tissue Rigidity. I. Experiments on Resonance Frequency and Tissue Rigidity Physiol. Plant. 1958, 11, 802-817.

115. Georget, D.; Smith, A.; Waldron, K. Modelling of carrot tissue as a fluid-filled foam. J. Materi. Sci. 2003, 38, 1933-1938.

116. Faisal, T.R.; Abad, E.M.K.; Hristozov, N.; Pasini, D. The impact of tissue morphology, cross-section and turgor pressure on the mechanical properties of the leaf petiole in plants. J. Bionic Eng. 2010, 7, S11-S23.

117. Lin, T.T.; Pitt, R. Rheology of apple and potato tissue as affected by cell turgor pressure. J. Texture Stud. 1986, 17, 291-313.

118. Karunasena, H.; Gu, Y.; Brown, R.; Senadeera, W. Numerical Investigation of Case Hardening of Plant Tissue During Drying and Its Influence on the Cellular-Level Shrinkage. Dry. Technol. 2015, 33, 713-734.

119. Pasini, D. On the biological shape of the Polygonaceae Rheum Petiole. Int. J. Des. Nat. Ecodynamics 2008, 3, 39-64.

120. Caringella, M.A.; Bergman, B.A.; Stanfield, R.C.; Ewers, M.M.; Bobich, E.G.; Ewers, F.W. Effects of phyllotaxy on biomechanical properties of stems of Cercis occidentalis (Fabaceae). Am. J. Bot. 2014, 101, 206-210.

121. Tadrist, L.; Darbois-Texier, B. Are leaves optimally designed for self-support? An investigation on giant monocots. J. Theor. Biol. 2016, 396, 125-131.

122. Chen, Y.; Chang, J.H.; Greenlee, A.S.; Cheung, K.C.; Slocum, A.H.; Gupta, R. Multi-turn, tension-stiffening catheter navigation system. In Proceedings of the 2010 IEEE International Conference on Robotics and Automation (ICRA), Anchorage, AK, USA, 3-7 May 2010; pp. 5570-5575.

123. Degani, A.; Choset, H.; Wolf, A.; Zenati, M.A. Highly articulated robotic probe for minimally invasive surgery. In Proceedings of the 2006 IEEE International Conference on Robotics and Automation, Orlando, FL, USA, 15-19 May 2006; pp. 4167-4172.

124. Sturges, R.H., Jr.; Laowattana, S. A flexible, tendon-controlled device for endoscopy. Int. J. Robot. Res. 1993, 12, 121-131.

125. Ota, T.; Degani, A.; Schwartzman, D.; Zubiate, B.; McGarvey, J.; Choset, H.; Zenati, M.A. A highly articulated robotic surgical system for minimally invasive surgery. Ann. Thorac. Surg. 2009, 87, 1253-1256.

126. Jung, J.; Penning, R.S.; Ferrier, N.J.; Zinn, M.R. A modeling approach for continuum robotic manipulators: Effects of nonlinear internal device friction. In Proceedings of the 2011 IEEE/RSJ International Conference on Intelligent Robots and Systems (IROS), San Francisco, CA, USA, 25-30 September 2011; pp. 5139-5146.

127. Raju, G.S.; Rex, D.K.; Kozarek, R.A.; Ahmed, I.; Brining, D.; Pasricha, P.J. A novel shape-locking guide for prevention of sigmoid looping during colonoscopy. Gastrointest. Endosc. 2004, 59, 416-419.

128. Rex, D.K.; Khashab, M.; Raju, G.S.; Pasricha, J.; Kozarek, R. Insertability and safety of a shape-locking device for colonoscopy. Am. J. Gastroenterol. 2005, 100, 817-820. 
129. Swanstrom, L.L.; Kozarek, R.; Pasricha, P.J.; Gross, S.; Birkett, D.; Park, P.O.; Saadat, V.; Ewers, R.; Swain, P. Development of a new access device for transgastric surgery. J. Gastrointest. Surg. 2005, 9, 1129-1137.

130. Chalhoub, M.S.; Kelly, J.M. Effect of bulk compressibility on the stiffness of cylindrical base isolation bearings. Int. J. Solids Struct. 1990, 26, 743-760.

131. Huh, T.M.; Park, Y.J.; Cho, K.J. Design and analysis of a stiffness adjustable structure using an endoskeleton. Int. J. Precis. Eng. Manuf. 2012, 13, 1255-1258.

132. Kim, Y.J.; Cheng, S.; Kim, S.; Iagnemma, K. Design of a tubular snake-like manipulator with stiffening capability by layer jamming. In Proceedings of the 2012 IEEE/RSJ International Conference on Intelligent Robots and Systems (IROS), Vilamoura, Portugal, 7-12 October 2012; pp. 4251-4256.

133. Kim, Y.J.; Cheng, S.; Kim, S.; Iagnemma, K. A novel layer jamming mechanism with tunable stiffness capability for minimally invasive surgery. IEEE Trans. Robot. 2013, 29, 1031-1042.

134. Zuo, S.; Iijima, K.; Tokumiya, T.; Masamune, K. Variable stiffness outer sheath with "Dragon skin" structure and negative pneumatic shape-locking mechanism. Int. J. Comput. Assist. Radiol. Surg. 2014, 9, 857-865.

135. Yagi, A.; Matsumiya, K.; Dohi, T. Slider Linkage Lock Mechanism using Air Pressure for Rigid-Flexible Outer Sheath for Endoscopic Surgery. In Proceedings of the 1st Asian Symposium on Computer Aided Surgery-Robotic and Image guided Surgery, National Institute of Advanced Industrial Science and Technology, Tokyo, Japan, 28 April 2005, pp. 194-197.

136. Yagi, A.; Matsumiya, K.; Masamune, K.; Liao, H.; Dohi, T. Rigid-flexible outer sheath model using shape lock mechanism by air pressure and wire driven curving mechanism. In Proceedings of the World Congress on Medical Physics and Biomedical Engineering 2006, Seoul, Korea, 27 August-1 September 2006; pp. 3108-3111.

137. Moses, M.S.; Kutzer, M.D.; Ma, H.; Armand, M. A continuum manipulator made of interlocking fibers. In Proceedings of the 2013 IEEE International Conference on Robotics and Automation (ICRA), Karlsruhe, Germany, 6-10 May 2013; pp. 4008-4015.

138. Loeve, A.J.; Plettenburg, D.H.; Breedveld, P.; Dankelman, J. Endoscope Shaft-Rigidity Control Mechanism: "FORGUIDE". IEEE Trans. Biomed. Eng. 2012, 59, 542-551.

139. Stilli, A.; Wurdemann, H.A.; Althoefer, K. A novel concept for safe, stiffness-controllable robot links. Soft Robot. 2017, 4, 16-22.

140. Shiva, A.; Stilli, A.; Noh, Y.; Faragasso, A.; De Falco, I.; Gerboni, G.; Cianchetti, M.; Menciassi, A.; Althoefer, K.; Wurdemann, H.A. Tendon-based stiffening for a pneumatically actuated soft manipulator. IEEE Robot. Autom. Lett. 2016, 1, 632-637.

141. Wurdemann, H.A.; Stilli, A.; Althoefer, K. Lecture notes in computer science: An antagonistic actuation technique for simultaneous stiffness and position control. In Proceedings of the International Conference on Intelligent Robotics and Applications, Portsmouth, UK, 24-27 August 2015; pp. 164-174.

142. Scarborough, S.E.; Cadogan, D.P. Applications of inflatable rigidizable structures. In Proceedings of the International SAMPE Symposium and Exhibition, Frederica, DE, USA, April 30-May 42006.

143. Philen, M. Force tracking control of fluidic flexible matrix composite variable stiffness structures. J. Intell. Mater. Syst. Struct. 2011, 22, 31-43.

144. Shan, Y.; Philen, M.; Lotfi, A.; Li, S.; Bakis, C.E.; Rahn, C.D.; Wang, K.W. Variable stiffness structures utilizing fluidic flexible matrix composites. J. Intell. Mater. Syst. Struct. 2009, 20, 443-456.

145. Philen, M.; Shan, Y.; Prakash, P.; Wang, K.; Rahn, C.; Zydney, A.; Bakis, C. Fibrillar network adaptive structure with ion-transport actuation. J. Intell. Mater. Syst. Struct. 2007, 18, 323-334.

146. Jafari, A.; Tsagarakis, N.G.; Caldwell, D.G. AwAS-II: A new actuator with adjustable stiffness based on the novel principle of adaptable pivot point and variable lever ratio. In Proceedings of the 2011 IEEE International Conference on Robotics and Automation (ICRA), Shanghai, China, 9-13 May 2011; pp. 4638-4643.

147. Jafari, A.; Tsagarakis, N.G.; Caldwell, D.G. A novel intrinsically energy efficient actuator with adjustable stiffness (AwAS). IEEE/ASME Trans. Mechatron. 2013, 18, 355-365.

148. Tagliamonte, N.L.; Sergi, F.; Carpino, G.; Accoto, D.; Guglielmelli, E. Design of a variable impedance differential actuator for wearable robotics applications. In Proceedings of the 2010 IEEE/RSJ International Conference on Intelligent Robots and Systems (IROS), Taipei, Taiwan, 18-22 October 2010; pp. 2639-2644. 
149. Aukes, D.; Kim, S.; Garcia, P.; Edsinger, A.; Cutkosky, M.R. Selectively compliant underactuated hand for mobile manipulation. In Proceedings of the 2012 IEEE International Conference on Robotics and Automation (ICRA), Saint Paul, MN, USA, 14-18 May 2012; pp. 2824-2829.

150. Nakabayashi, M.; Kobayashi, R.; Kobayashi, S.; Morikawa, H. Bioinspired propulsion mechanism using a fin with a dynamic variable-effective-length spring. J. Biomech. Sci. Eng. 2009, 4, 82-93.

151. Hunter, I.W.; Lafontaine, S. A comparison of muscle with artificial actuators. In Proceedings of the IEEE 5th Technical Digest Solid-State Sensor and Actuator Workshop, Hilton Head Island, SC, USA, 22-25 June 1992; pp. 178-185.

152. Jung, D.; Blangé, T.; De Graaf, H.; Treijtel, B. Elastic properties of relaxed, activated, and rigor muscle fibers measured with microsecond resolution. Biophys. J. 1988, 54, 897-908.

153. Paetsch, C.; Trimmer, B.; Dorfmann, A. A constitutive model for active-passive transition of muscle fibers. Int. J. Non-Linear Mech. 2012, 47, 377-387.

154. Shoa, T.; Munce, N.R.; Yang, V.; Madden, J.D. Conducting polymer actuator driven catheter: Overview and applications. Proc. SPIE 2009, 7287, 72871J.

155. McEvoy, M.A.; Correll, N. Materials that couple sensing, actuation, computation, and communication. Science 2015, 347, 1261689.

156. Breedveld, P.; Sheltes, J.; Blom, E.M.; Verheij, J.E. A new, easily miniaturized steerable endoscope. IEEE Eng. Med. Biol. Mag. 2005, 24, 40-47.

157. Catherine, J.; Rotinat-Libersa, C.; Micaelli, A. Comparative review of endoscopic devices articulations technologies developed for minimally invasive medical procedures. Appl. Bionics Biomech. 2011, 8, 151-171.

158. Wehrmeyer, J.; Barthel, J.; Roth, J.; Saifuddin, T. Colonoscope flexural rigidity measurement. Med. Biol. Eng. Comput. 1998, 36, 475-479.

159. Trejos, A.L.; Jayaraman, S.; Patel, R.V.; Naish, M.D.; Schlachta, C.M. Force sensing in natural orifice transluminal endoscopic surgery. Surg. Endosc. 2011, 25, 186-192.

160. Varadarajulu, S.; Banerjee, S.; Barth, B.A.; Desilets, D.J.; Kaul, V.; Kethu, S.R.; Pedrosa, M.C.; Pfau, P.R.; Tokar, J.L.; Wang, A.; et al. GI endoscopes. Gastrointest. Endosc. 2011, 74, 1-6.

161. Haga, Y.; Mineta, T.; Esashi, M. Multi-functional active catheter. Sens. Update 2000, 8, 147-186.

162. Okamura, A.M.; Simone, C.; O'leary, M.D. Force modeling for needle insertion into soft tissue. IEEE Trans. Biomed. Eng. 2004, 51, 1707-1716.

163. Yarmolenko, P.S.; Moon, E.J.; Landon, C.; Manzoor, A.; Hochman, D.W.; Viglianti, B.L.; Dewhirst, M.W. Thresholds for thermal damage to normal tissues: An update. Int. J. Hyperth. 2011, 27, 320-343.

164. Henke, M.; Gerlach, G. On the development of planar actuators for variable stiffness devices. Proc. SPIE 2013, 8687, 868727-868727.

165. Islam, A.; Hansen, H.N.; Tang, P.T.; Sun, J. Process chains for the manufacturing of molded interconnect devices. Int. J. Adv. Manuf. Technol. 2009, 42, 831-841.

166. Cheng, W.B.; Moser, M.A.; Kanagaratnam, S.; Zhang, W.J. Overview of upcoming advances in colonoscopy. Dig. Endosc. 2012, 24, 1-6.

167. Loeb, J.; Plantif, B.E. System of Protection by Modeling. US Patent 4,045,830, 6 September 1977.

168. Coppard, B.M.; Lohman, H. Introduction to Splinting; Elsevier Health Sciences: Amsterdam, The Netherlands, 2008.

169. Fukuda, T.; Guo, S.; Kosuge, K.; Arai, F.; Negoro, M.; Nakabayashi, K. Micro active catheter system with multi degrees of freedom. In Proceedings of the 1994 IEEE International Conference on Robotics and Automation, San Diego, CA, USA, 8-13 May 1994; pp. 2290-2295.

170. Wache, H.; Tartakowska, D.; Hentrich, A.; Wagner, M. Development of a polymer stent with shape memory effect as a drug delivery system. J. Mater. Sci.: Mater. Med. 2003, 14, 109-112.

171. Metcalfe, A.; Desfaits, A.C.; Salazkin, I.; Yahia, L.; Sokolowski, W.M.; Raymond, J. Cold hibernated elastic memory foams for endovascular interventions. Biomaterials 2003, 24, 491-497.

172. Faddis, M.N.; Blume, W.; Finney, J.; Hall, A.; Rauch, J.; Sell, J.; Bae, K.T.; Talcott, M.; Lindsay, B. Novel, magnetically guided catheter for endocardial mapping and radiofrequency catheter ablation. Circulation 2002, 106, 2980-2985.

173. Schiemann, M.; Killmann, R.; Kleen, M.; Abolmaali, N.; Finney, J.; Vogl, T.J. Vascular Guide Wire Navigation with a Magnetic Guidance System: Experimental Results in a Phantom 1. Radiology 2004, 232, 475-481. 
174. Naito, H.; Akazawa, Y.; Tagaya, K.; Matsumoto, T.; Tanaka, M. An ankle-foot orthosis with a variable-resistance ankle joint using a magnetorheological-fluid rotary damper. J. Biomech. Sci. Eng. 2009, 4, 182-191.

175. Campanaro, L.; Goldstone, N.; Shepherd, C. Rigidized Evacuated Structure. US Patent 3,258,883, 5 July 1966.

176. Zinner, N.R.; Sterling, A.M. Penile Prosthesis and Method. US Patent 5,069,201, 30 September 1991.

177. Bauerfeind, P.; Bauerfeind, H. Tubular Inserting Device with Variable Rigidity. US Patent 5,337,733, 16 August 1994.

178. Bureau, M.; Jung, J.H.; Keller, T. Fitting Element with Controlled Stiffness. US Patent Application 13/520,102 2009, 14 June 2012.

179. Bureau, M.; Keller, T.; Veneman, J.F.; MARTIN, C.V. Element with Variable Stiffness Controlled by Negative Pressure. US Patent Application 14/369,766, 24 December 2015.

180. Masters, B.P.; Van Schoor, M.C. Variable Stiffness Shaft. US Patent 6,361,451, 26 March 2002.

181. Brenneman, R.; Ewers, R.; Saadat, V.; Chen, E. Apparatus and Methods for Guiding an Endoscope via a Rigidizable Wire Guide. US Patent Application 10/757,980 2004, 23 September 2004.

182. Rudloff, D.A. Penile Implant. US Patent 4,664,100, 28 May 1987.

183. Olson, G. Medical Devices with Variable Stiffness. US Patent 8,376,960, 19 Fabruary 2013.

184. Eidenschink, T.E. Variable Manipulative Strength Catheter. US Patent 7,291,127, 6 November 2007.

185. Smith, K.W.; Palmer, M.A.; Deville, D.D.; McBrayer, S.M.; Kline, K.R. Catheter with Controllable Stiffness and Method for Operating a Selective Stiffening Catheter. US Patent 7,559,916, 14 July 2009.

186. Sokolowski, W. Cold Hibernated Elastic Memory Self-Deployable and Rigidizable Structure and Method Therefor. US Patent 6,702,976, 9 March 2004.

187. Larson, L. Thermoplastic Splint or Cast. US Patent 3,809,600, 10 December 1974.

188. Patel, J.I. Endoscope Having Variable Flexibility. US Patent 4,815,450, 28 March 1989.

189. Griffin, S. Selectively Flexible Catheter and Method of Use. US Patent 7,828,790 9 November 2010.

190. Thill, C.; Etches, J.; Bond, I.; Potter, K.; Weaver, P. Morphing skins. Aeronaut. J. 2008, 112, 117-139.

191. Weisshaar, T.A. Morphing aircraft systems: Historical perspectives and future challenges. J. Aircr. 2013, 50, 337-353.

192. Laschi, C.; Cianchetti, M. Soft robotics: New perspectives for robot bodyware and control. Front. Bioeng. Biotechnol. 2014, 2, 3.

193. Park, Y.J.; Jeong, U.; Lee, J.; Kim, H.Y.; Cho, K.J. The effect of compliant joint and caudal fin in thrust generation for robotic fish. In Proceedings of the 2010 3rd IEEE RAS and EMBS International Conference on Biomedical Robotics and Biomechatronics (BioRob), Tokyo, Japan, 26-29 September 2010; pp. 528-533.

194. Park, Y.J.; Jeong, U.; Lee, J.; Kwon, S.R.; Kim, H.Y.; Cho, K.J. Kinematic condition for maximizing the thrust of a robotic fish using a compliant caudal fin. IEEE Trans. Robot. 2012, 28, 1216-1227.

195. Park, Y.J.; Cho, K.J. Design and manufacturing a bio-inspired variable stiffness mechanism in a robotic dolphin. In Proceedings of the International Conference on Intelligent Robotics and Applications, Seoul, Korea, 25-28 September 2013; pp. 302-309.

196. Chu, W.S.; Lee, K.T.; Song, S.H.; Han, M.W.; Lee, J.Y.; Kim, H.S.; Kim, M.S.; Park, Y.J.; Cho, K.J.; Ahn, S.H. Review of biomimetic underwater robots using smart actuators. Int. J. Precis. Eng. Manuf. 2012, 13, 1281-1292.

197. Park, Y.J.; Lee, J.G.; Jeon, S.; Ahn, H.; Koh, J.; Ryu, J.; Cho, M.; Cho, K.J. Dual-stiffness structures with reconfiguring mechanism: Design and investigation. J. Intell. Mater. Syst. Struct. 2016, 27, 995-1010.

198. Wang, L.; Melnik, R.V. Nonlinear dynamics of shape memory alloy oscillators in tuning structural vibration frequencies. Mechatronics 2012, 22, 1085-1096.

199. Giataganas, P.; Evangeliou, N.; Koveos, Y.; Kelasidi, E.; Tzes, A. Design and experimental evaluation of an innovative SMA-based tendon-driven redundant endoscopic robotic surgical tool. In Proceedings of the 19th Mediterranean Conference on Control \& Automation (MED), Corfu, Greece, 20-23 June 2011; pp. 1071-1075.

200. Majidi, C. Soft robotics: A perspective-Current trends and prospects for the future. Soft Robot. 2014, $1,5-11$.

201. Nemirovskii, M.; Kuz'min, A. Investigation of the flexural and torsional rigidity of flexible elements of endoscopes. Biomed. Eng. 1984, 18, 214-217. 
202. Delaplace, A.; Gatuingt, F.; Ragueneau, F. Aide-Mémoire de Mécanique des Structures: Résistance des Matériaux; Dunod: Paris, France, 2008. (In French)

203. Cheng, W. Development of a Kinetic Model for Loop-Free Colonoscopy Technology. Ph.D. Thesis, University of Saskatchewan, Saskatoon, SK, Canada, 2014.

204. Bell, G.; Burn, K. Measurement of the stiffness of endoscopes-A plea for commonality. Gut 2001, 49, doi:10.1136/gut.49.1.154.

205. Dogramadzi, S.; Bell, G.; Bicker, R.; Burn, K. A novel system to rapidly analyse the flexural rigidity of endoscopes used in colonoscopy and flexible sigmoidoscopy. Int. J. Cond. Monit. Diagn. Eng. Manag. 2003, 6, 24-32.

206. Dogramadzi, S.; Burn, K.; Bicker, R.; Bell, G. The effect of temperature on the flexural rigidity of various commercially available colonoscopes and gastroscopes. Gut 2002, 50, A41.

207. Sullivan, M.J. Variable stiffening device for colonoscopy. Gastrointest. Endosc. 1990, 36, 642-643.

(C) 2017 by the authors. Licensee MDPI, Basel, Switzerland. This article is an open access article distributed under the terms and conditions of the Creative Commons Attribution (CC BY) license (http:/ / creativecommons.org/licenses/by/4.0/). 